\title{
A service science approach for improving healthy food experiences
}

Citation for published version (APA):

Mahr, F. D., Kalogeras, N., \& Odekerken-Schröder, G. J. (2013). A service science approach for improving healthy food experiences. Journal of Service Management, 24(4), 435-471.

https://doi.org/10.1108/JOSM-04-2013-0089

Document status and date:

Published: 01/01/2013

DOI:

10.1108/JOSM-04-2013-0089

Document Version:

Publisher's PDF, also known as Version of record

Document license:

Taverne

Please check the document version of this publication:

- A submitted manuscript is the version of the article upon submission and before peer-review. There can be important differences between the submitted version and the official published version of record.

People interested in the research are advised to contact the author for the final version of the publication, or visit the DOI to the publisher's website.

- The final author version and the galley proof are versions of the publication after peer review.

- The final published version features the final layout of the paper including the volume, issue and page numbers.

Link to publication

\footnotetext{
General rights rights.

- You may freely distribute the URL identifying the publication in the public portal. please follow below link for the End User Agreement:

www.umlib.nl/taverne-license

Take down policy

If you believe that this document breaches copyright please contact us at:

repository@maastrichtuniversity.nl

providing details and we will investigate your claim.
}

Copyright and moral rights for the publications made accessible in the public portal are retained by the authors and/or other copyright owners and it is a condition of accessing publications that users recognise and abide by the legal requirements associated with these

- Users may download and print one copy of any publication from the public portal for the purpose of private study or research.

- You may not further distribute the material or use it for any profit-making activity or commercial gain

If the publication is distributed under the terms of Article $25 \mathrm{fa}$ of the Dutch Copyright Act, indicated by the "Taverne" license above, 


\title{
A service science approach for improving healthy food experiences
}

\author{
Dominik Mahr and Nikos Kalogeras \\ Department of Marketing and Supply Chain Management, \\ School of Business and Economics, Maastricht University, \\ Maastricht, The Netherlands, and \\ Gaby Odekerken-Schröder \\ Service Science Factory, School of Business and Economics, \\ Maastricht University, Maastricht, The Netherlands
}

\begin{abstract}
Purpose - Insufficient attention to the specific nature of healthy food experiences might limit the success of related innovations. The purpose of this article is to adopt a value-in-use perspective to conceptualize healthy food consumption as experiential and emotional, rather than the mere intake of nutrition, and to examine the development of healthy food communication with a service science approach.

Design/methodology/approach - With a service science approach, this study proposes a virtual healthy food platform for children. The key data come from internal project documents, workshops with children and other stakeholders (e.g. parents, teachers), and interviews with project team members.

Findings - The simultaneity of functional and hedonic benefits, implications for multiple stakeholders, social norms, and need for expertise characterize healthy food experiences. The proposed framework accounts for enablers, principles, outcomes, and challenges affecting the development of communication integral to healthy food experiences, using project data and tools as illustrations.

Research limitations/implications - This study contributes to growing literature on service science by introducing key principles and contingency factors that influence the success of experience-centric service innovations. Quantitative research should validate the established framework and investigate the elements' relative usefulness for developing healthy food communication.

Practical implications - The service science approach involves multiple stakeholders, empathic data collection, and visual tools to develop an entertaining platform to help children learn about healthy food.

Originality/value - This research conceptualizes and validates healthy food experiences as value-in-use offerings. The proposed service science approach accounts for the interactions among stakeholders, the holistic nature, and specificities of a real-life decision context for improving healthy food experiences.
\end{abstract}

Keywords Healthy food, Value-in-use, Service design, Innovation, Service science, Experience

Paper type Research paper

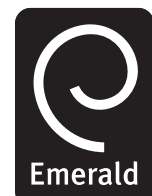

The authors thank Laszlo Determann, Silvia Lleras, and Verena Wimmer for their assistance during the data collection, Robert Ciuchita for his feedback on a previous version of this study, and Kokkerelli for supporting this research project. This manuscript was selected and guest edited by Dr Sabine Möller, EBS Business School, Germany to represent service science and the "health-food-marketing triangle".

Journal of Service Management

Vol. 24 No. 4,2013 pp. $435-471$

(c) Emerald Group Publishing Limited $1757-5818$

DOI 10.1108/JOSM-04-2013-0089 
JOSM 24,4

436

\section{Introduction}

According to the World Health Organization, worldwide obesity rates have more than doubled since 1980; 68 percent of the USA and almost half of European adults are overweight or obese (Flegal et al., 2010). These and other developments have moved information about healthy, safe, and nutritious food items to the top of service providers', marketing researchers', and policy makers' agendas. Yet recent figures suggest the limited success of US and EU policies that aim to enhance healthy food education, information, and consumption. Such ineffective communication might explain the high failure rates of innovations related to food (Francis et al., 2008) and the limited success of safe food policies, which often fail to address specific customer segments, related stakeholders, or food producers (Costa and De Jonge, 2006; Trail and Meulenberg, 2002).

A key reason for the 80 percent average failure rate for healthy food innovations may be that communications about them reflect the foods' newness, benefits, and risks (Grunert et al., 1997; Tijhuis et al., 2012), rather than accounting for the specific nature of the experiences associated with healthy food education, information, and consumption. Such an experience occurs when a company intentionally uses services (e.g. online games, cooking workshops) as the stage, and goods as support (e.g. aprons, cookbook) to engage individual customers in a way that creates a memorable event (Pine and Gilmore, 1998). Innovating these complex healthy food experiences often involves many stakeholders, including health insurance companies, doctors, industry groups, and governmental organizations. With regard to the societal implications of unhealthy food consumption, they are particularly pronounced for children, whose prior knowledge about healthiness tends to be limited and whose food intake is influenced by various stakeholders (e.g. parents, grandparents, teachers; Calvert, 2008). A sole focus on healthy food also might make children reluctant to consume, because healthy food appears as something they must eat to avoid sickness or negative effects, rather than something they want to eat (Berry and Bendapudi, 2007; McColl-Kennedy et al., 2012; Wansink et al., 2009). Thus, customers' subjective assessments of the value of healthy food depend on their engagement in communication with other stakeholders during the experience (Wansink et al., 2009; Winter Falk et al., 2001). Both food companies and public institutions also increasingly attempt to convey important health-related lessons (e.g. need for physical activity, obesity prevention) and specific values (e.g. highly affective advocates) to children.

To advance communication about healthy food innovations though, it may be more important to view food consumption as experiential and emotional (Conner et al., 1999; Korsmeyer, 2005). Framing food consumption as experiential acknowledges that taste is subjective and overall quality assessments are always contextual (Loewenstein et al., 2007). In essence, a healthy food experience relies on subjective interpretations of interrelated encounters with food that improve the consumer's well-being. The development of new food experiences thus demands a more holistic approach than suggested by existing conceptualizations that ignore the influence of contextual aspects on the communication about and delivery of value related to healthy eating processes.

Together, the number and variety of stakeholders involved, the experiential nature of healthy food consumption, and the reluctance of consumers to eat healthy food also indicate the need for a holistic view on communication about healthy food experiences, which service providers can use to develop and deliver new consumption experiences. 
Yet, no research captures this holistic experience. Researchers investigate healthy, safe food innovations and identify several success factors, such as nutrition levels, taste, and quality labels, but they often neglect experiential aspects (Drewnowski, 1997; Grunert et al., 1997), even as more recent research reveals that experiences comprises both functional/objective and experiential/subjective benefits (Belei et al., 2013; Costa and Jongen, 2006; Pine and Gilmore, 1998). Furthermore, food consumption has implications beyond the individual consumer, especially considering the rising costs of health care for society at large (Zimmet et al., 2001). For children especially, food choices may affect their health care demands in the long run, which remain difficult for policy makers, health care providers, and insurers to predict. We propose that food choice is driven by both the core food item and the augmented experience offer surrounding that item (e.g. packaging, context; Storey and Easingwood, 1998). Consumption and its assessment thus depend heavily on individual perceptions and interactions with others, especially if the consumer possesses limited prior knowledge (e.g. children) and is strongly influenced by food gatekeepers (e.g. parents) (Calvert, 2008; Cullen et al., 2001).

However, existing research often studies food attribute cues in laboratories, without considering real-world product cues and environments (Pennings et al., 2005). Our investigation of healthy food experiences involves different stakeholders across different service systems (e.g. children, parents, teachers in schools, sports clubs, families). The value-in-use perspective from the service-dominant logic also moves beyond a product focus to consider a wide set of experience determinants (Vargo and Lusch, 2008). Despite its advantages, the premises of this approach remain relatively abstract and difficult to apply, with uncertain links to other theories. Its applicability for improving healthy food experiences also remains unproven (Lusch and Vargo, 2006). We advance existing literature by defining key elements for developing new communications related to healthy food experience.

To investigate these healthy food experiences, we propose using a service science perspective, defined as "the study of service systems, aiming to create a basis for systematic service innovation" (Maglio and Spohrer, 2008, p. 18), in which the service systems entail value co-creation configurations of people, technology, and value propositions (connecting internal and external service systems and shared information). The service-dominant logic offers a philosophical foundation for service science, such that the service system is its basic theoretical construct, and service design represents a toolbox for investigating service systems (Mager, 2009; Maglio and Spohrer, 2008; Patrício et al., 2008). Therefore, service science aims to offer a comprehensive, experience-centric view of service innovation that incorporates different stakeholders of the service system (Ostrom et al., 2010). This study will be summarized in a conceptual framework with key elements (enabler, principles, challenges, and outcomes) of service-science based new service developments. We encourage service and innovation scholars to validate this framework of principles beyond the setting of healthy food experiences. Specifically:

- What defines a healthy food experience taking a value-in-use perspective?

- What are the key elements for developing new communication about healthy food experiences?

- What are the key elements of service-science based new service developments?

We thus view a healthy food experience as an augmented service offering that includes both the healthy food item and its accompanying service experiences, from which the
A service science approach

437 
JOSM 24,4

438 customer and stakeholders across service systems extract functional and hedonic benefits. With this approach, we make several key contributions. First, we contribute to food innovation literature by adopting an experience perspective, which views healthy food innovations as augmented offerings that include accompanying service experiences, such as communication about the core product. We also consider the behavioral habits of customers, who often trade off functional and hedonic attributes in their healthy food consumption processes, and we suggest ways to communicate these attributes in a real-life decision context. Our empirical study follows a typical service science approach to innovation, in which customers' co-creation caters to needs related to the experiential consumption of healthy food, interactions with other stakeholders, and affective and cognitive decision-making criteria.

Second, we extend the application of the service-dominant logic by conceptualizing and validating the healthy food experience as a value-in-use offering. Growing research on healthy food experiences tends to be conceptual and abstract; we emphasize the experiential, multilayered nature of healthy food and demonstrate the need for a holistic approach to the experience of its consumption. In addition, we account for customers' active role in determining value and thus empirically explore the core premises of the service-dominant logic, service science, and services marketing, to offer recommendations for a holistic view of healthy food experiences.

Third, this study contributes to growing literature on service science by examining key principles and contingency factors that influence the success of experience-centric service innovations. Communication about healthy food is an experiential offer, with a series of customer touch points and roles captured by service design tools in a holistic service science approach. To advance literature on service science, we establish a framework with principles, enablers, challenges, and outcomes that accounts for the nature of experiences and their innovation process. Research and practice in marketing, innovation, and services should benefit from this empirically grounded identification of success criteria for implementing an experiential offer.

In the next section, we review relevant literature on (healthy) food, marketing, innovation, and service design to develop an experiential perspective on innovations that can support communication about healthy food experiences. Then we present our research methodology, involving in-depth analysis of a real-life case to develop a virtual platform to inform children about healthy food. We present and discuss our results, which provide empirical evidence of which factors are most critical for innovating healthy food communication. Finally, we conclude with theoretical and managerial implications.

\section{Literature and conceptual development}

To improve communication about healthy food experiences, we suggest a value-in-use approach. Emphasis is placed on the experiential nature of food as an augmented service offering, which we address using multiple stakeholders' perspectives, in accordance with a service science approach.

\section{Defining a healthy food experience}

We draw from several literature streams to conceptualize the experience-centric, and therefore customer-centric, character of a healthy food experience. This offering encompasses both tangible and intangible dimensions, in line with the augmented service perspective on food consumption (Storey and Easingwood, 1998) and recent 
advances in the social sciences that view food experiences as both physical needs and emotional processes with various contextual aspects and distinct meanings for stakeholders (Hult et al., 2011; McColl-Kennedy et al., 2012). For example, customers' nutritional knowledge may affect their eating habits and consumption patterns, but so might dynamic, contextual aspects of the decision environment or relevant mental associations with a specific food (Wansink, 2004).

Customers form their preferences through experience with healthy food attributes and cues that reflect (observable or latent) elements of the decision context (Bettman et al., 1998). Recent studies (Papies et al., 2007; Verbeke et al., 2009) show that communications about healthy food offerings often lead consumers to perceive them as functional (or not hedonic), expensive, and low in market availability. Some customers may be reluctant to purchase healthy food because they lack any association with their desired lifestyle or cannot afford it (Kalogeras et al., 2009). The lack of opportunity to experience healthy food then may cause customers to assign low importance to its attributes and communication cues.

The service-dominant logic, as the philosophical basis for service science (Maglio and Spohrer, 2008), argues that goods represent distribution mechanisms for services (stated in the third foundational premise (FP) as modified by Vargo and Lusch (2008)). Thus, we argue that a healthy food item mainly represents a distribution mechanism for the holistic healthy food experience. As Vargo and Lusch (2008) reason, manufacturers of healthy food cannot deliver value but instead offer value propositions (FP 7), so the value of a holistic healthy food experience ultimately is determined by its beneficiaries (FP 10). In contrast with value-in-exchange, value-in-use implies that consumers use their knowledge and skills to co-create value during the healthy food experience (FP 1), and their participation in the communication, smelling (olfactory system), touching (tactile system), or tasting (gustatory system) (Peck and Childers, 2003) and intake of healthy food[1] ultimately increases their well-being. This value-in-use thus relates not only to eating healthy food but also to experiential aspects, preceding tasting.

So the healthy food product itself does not result in value until its consumption (Edvardsson et al., 2011; Patrício et al., 2008), which is influenced by the communication accompanying it. Zomerdijk and Voss (2010, p. 67) define a service as an experience that occurs "when a customer has any sensation or acquires knowledge from some level of interaction with the elements of a context created by a service provider." We similarly conceive of a healthy food experience as a value-in-use proposition involving different service systems, which demands a more holistic research approach than existing conceptualizations that ignore the influence of the context on the delivery of value in healthy consumption processes (FP 10). In Pine and Gilmore's (1998) terminology, we argue that a healthy food experience occurs when a company intentionally uses services (e.g. online games, cooking workshops) as the stage, and goods as support (e.g. aprons, cookbook), to engage individual customers in a way that creates a memorable (and favorable) event during the interaction with healthy food.

To identify the key contextual aspects, we consider the dynamic nature of relevant communication activities and processes that form health-related values, created through interactions among stakeholders (Hult et al., 2011). The dynamic nature of decision contexts also implies multiple configurations of resources (e.g. people, technology, organizations, shared information) for value co-creation (Maglio and Spohrer, 2008). A service provided by one system (e.g. the firm) contains a subset of the resources that
A service science approach

439 
JOSM 24,4

440

must be communicated and integrated to be perceived as valuable by another system (e.g. the customer) (Edvardsson et al., 2011; Grönroos, 2011). If we apply this logic to healthy food, different resources must be communicated about and integrated to create nutrition in a home-cooked meal: the services provided by farmers; market-facing resources such as other ingredients, utensils, monetary resources, fuel, and transportation; nonmarket-facing personal resources such as knowledge about nutrition, purchasing, cooking, or the suggestions and assistance of friends and family; and public resources, including quality assurance schemes for food and drugs (Vargo and Akaka, 2009). After conceptualizing healthy food experience, the following section synthesizes different literature stream on how to improve such experiences.

\section{Improving the healthy food experience}

Successful food companies often integrate their R\&D and marketing tactics to introduce the technologically innovative food offerings demanded by different customer segments (Grunert et al., 1997; Trail and Meulenberg, 2002). An example of a technological innovative food offering is giant raisins, labeled Graisins. Their seeds have been genetically re-programmed to grow far beyond its normal size while they taste exactly the same as the typical, small raisins. Graisins meet the Asian demand for large fruits of all kinds, in particular of the Japanese market. Yet prior product innovation research (little of which is specifically oriented toward healthy food), with its product-centric view, offers few insights into communication about healthy food innovations, nor does it account for wider interactions among multiple stakeholders, who may have the same, similar, or different food experiences (McColl-Kennedy et al., 2012). A service science approach using service design tools can help develop effective communication through experience-centric services (Helkkula et al., 2012), which get realized with customers' involvement and through the development of interactions with stakeholders (FP 9). The dynamic nature of these interactions and the changing idiosyncrasies of the decision environment that surround the experience cannot be controlled fully by firms (Zomerdijk and Voss, 2010). As opposed to a product-centric view that focuses on product attributes, the service-dominant logic is customer-oriented and requires adaptations to customer thinking to create value (Michel et al., 2008).

When focusing on food experience, the consideration of an individual's biases are central in explaining his or her behavior. Most such biases are related to environmental cues of the consumption context. Studies on external eating (i.e. eating in response to environmental cues rather than internal hunger) explain that it may be attributed to the so-called selective attention bias of customers while ignoring other cues such as physiological hunger. Hence, external eaters are more inclined, for instance, to snacks which are shelved close to a cash register in the supermarket (Newman et al., 2008). In such a situation, customers may increase awareness of the immediate environment and decrease awareness of the self (O'Connor et al., 2008). Besides, selective attention, customers may exhibit several information processing biases that operate throughout all aspects of cognition regarding specific situations of eating disorders or anxiety (Teachman et al., 2007). Rather than engaging in a full cognitive elaboration, customers activate heuristic procedures to simplify cognitive processing requirements. For example, a "low fat" label would lead consumers to over consume these foods in such a way that, even considering the reduced calories of the low-fat food, customers would gain 34 percent more calories (Wansink et al., 2009). Finally, customers may be subject to the present-bias 
which refers to individuals' desire for instant-gratification and, as a result, increase their (unhealthy) eating volume (Fudenberg and Levine, 2006). Hence, storing unhealthy food in less convenient locations (Loewenstein et al., 2009) and making healthy food experiences more convenient may lead to a more healthy food experience. Overall, attentional, information processing and present biases of customers' preferences may be exploited in order to help customers rather than harm them (van Ittersum and Wansink, 2013). In the context of developing healthy food experiences for children, subtle changes in the path of least resistance may potentially result in major changes in children's food choices (Loewenstein et al., 2007). For instance, healthy foods and juices could be served in convenient containers in school buildings and gyms that would facilitate easy access, allowing pupils more free time for other desired activities, whereas less healthy foods and soft drinks' vending machines could be located in less accessible places, hence attracting pupils' attention to a lesser extent.

Because typical innovation processes for healthy food rely on a product-centric view, they may be unsuitable for advancing communication about healthy food experiences. These innovation processes also tend to employ research approaches and methods such as surveys or laboratory studies that neglect the natural consumption environment (Stickdorn and Schneider, 2010). Moreover, customers' decision-making processes as a series of concrete, problem-solving steps, with the assumption that customers recognize their needs, assess several alternatives, and then purchase and consume. Accordingly, these approaches and methods suggest that customers weigh the functional (food) attributes in terms of their importance, make comparative trade-offs between attributes, and rank order attributes and food items according to their overall utility.

Instead, most customers assume the functional attributes and quality of food items as given (Ward and Mann, 2000), such that an emphasis on functionality may prompt predictions of decreased hedonic value, because of the associations that specific customer segments attach to healthy food items (Dhar and Wertenbroch, 2000; Raghunathan et al., 2006). That is, functional and hedonic stimuli may be negatively correlated, such that claims of healthier food make it seem less enjoyable, which creates an affective-cognitive conflict for consumers (Shiv and Fedorikhin, 1999). Furthermore, modern customers demand food products that feature experience-based marketing campaigns and stimulating communications that reflect their lifestyles (Pine and Gilmore, 1998; Wansink, 2004). They want food products that deliver an experience, which necessarily entails more than one stakeholder (e.g. service creator, supplier, distributor, retailer, marketer, customer; Livingstone, 2006; Ward and Mann, 2000). The experience also may comprise both functional/objective attributes (health, safety) and hedonic/subjective attributes (pleasure, fun) (Belei et al., 2013). The interplay between these two clusters of attributes is of crucial importance for segments such as children whose food-related decisions depend on and are influenced by closely related stakeholders' (e.g. parents, teachers) own consumption patterns and purchasing behaviors (Wansink et al., 2013). Lack of nutritional knowledge, resistance to caretakers, receptivity to advertising, and limited experience may cause children in particular to prefer hedonic over the functional experiences that their caretakers view as best (i.e. "more healthy") (Livingstone, 2006).

Service design tools, such as customer journeys, that capture both cognitions and feelings, can help reveal the interplay among such experiences and account for the characteristics of the experience environments that affect the formation of consumers'
A service science approach

441 
JOSM 24,4

442

perceptions and possibly their biased preferences (Mager, 2009). The recognition and exploitation of this interplay should advance our understanding of how customers may alter incentives for healthy food experiences, such that healthier food choices also become easier to choose.

From this discussion and prior research on experiential consumption (Holbrook and Hirschman, 1982; Ostrom et al., 2010; Pine and Gilmore, 1998) and the value-in-use perspective (Lusch and Vargo, 2006; Storey and Easingwood, 1998; Vargo and Lusch, 2008), we expect that communication about healthy food experience entails a multilayer decision-making process involving various tangible and intangible resources. The experiential nature of these tangible and intangible resources, as well as the tangibility of any outcomes, may result in greater value perceptions and loyalty to a specific (performance) goal (Geyskens et al., 2008; Palmatier et al., 2007) such as improving communications about healthy food experiences.

Our nuanced empirical method thus adopts key principles of the service science approach, using service design tools that account for real-world experience through observation and scenarios and recognizes the influence of multiple stakeholders. Although the service science approach appears well matched with communication about healthy food experiences, limited evidence exists, so we develop a holistic framework for innovating communications about experience-centric healthy food.

\section{Methodology}

Our exploratory investigation aims to acquire a more fundamental understanding of ways to develop new means of communicating about healthy food experiences. From a service science perspective, healthcare in general, and healthy food in particular, is a new, under researched phenomenon (Ostrom et al., 2010), making qualitative research a suitable method. We employ a case study approach to investigate this phenomenon in its real-life context and develop theoretical insights (Eisenhardt and Graebner, 2007; Yin, 2008). In line with a grounded theory approach, we elicited the results from the case study data and matched them with our literature review using recursive cycling across qualitative data, emerging theory, and extant literature (Dul and Hak, 2007; Glaser and Strauss, 1967).

\section{Research setting}

Our unit of analysis is the innovation project which is the typical means to develop a specific innovation. The literature review indicated several selection criteria for a suitable case - an innovation project that:

- aims to improve communication about healthy food experiences;

- features consumers reluctant to consume healthy food; and

- involves multiple stakeholders.

Therefore, we chose an innovation project that centers on informing, educating, and motivating children between six and 16 years of age in relation to healthy food. The innovation project was conducted by the Service Science Factory (SSF) of Maastricht University. Its central element is the development of a virtual platform, on which children learn through experiencing play, games, and entertainment. The platform is tied to offline resources, to facilitate practice with cooking, growing fruits and vegetables, test shopping, and other food-related experiences. The case is called 
"Kids University for Cooking" (KU4C) and appropriate for this study for several reasons. First, KU4C focuses on the functional benefits of an offering but also places a strong emphasis on hedonic benefits when communicating about the augmented offering, such as play and fun, to help consumers learn, seemingly effortlessly, about healthy food experiences. Second, the particular reluctance of children to consume food and their greater proneness (compared with adults) to unhealthy choices suggests that we can probe these key characteristics of the healthy food experience. Third, KU4C includes multiple stakeholders, such as parents, grandparents, food producing firms, teachers, industry associations, schools, and government organizations in its efforts and validates the results with them.

The SSF is an innovative place where students, researchers, and professionals work in a pressure-cooker environment on inventing new or improving existing services. A typical innovation project at SSF lasts 12 weeks in total, including preparation and completion. The KU4C project involved ten team members who worked for eight weeks on the service innovation project. The team members reflected diverse areas of expertise. One of the team members was the project manager, mainly focusing on the process of the innovation project. Two team members were knowledgeable about innovations in services research, focusing on a holistic approach for communicating about this healthy food experience. Two other project team members specialized in food research (one combined with psychology) and could provide expertise related to this aspect of the project. One member completed a study in dentistry and therefore offered a health care perspective to the project team. Finally, three team members were trained in service design, guiding the team in how to benefit from applying service design tools (Table I). The innovation project was commissioned by a horticultural food company, Kokkerelli, and received financial support from the regional government. A typical service innovation process at the SSF consists of three stages (visualized in Appendix 1). The team met every week for roughly half a day to co-create, discuss, and synthesize insights; in addition, sub teams met to work on specified tasks.

In the first seek stage of the service innovation process, the project team members sought the origins of the current problem or an idea a client wants to realize, looked at key stakeholders, and attempted to understand their needs and wants, through desk

\begin{tabular}{llcc}
\hline Identification & Specialization & Length (h) & Experience (years) \\
\hline Interviews & & & \\
Int1 & Services research, healthy food & $0: 18$ & 17 \\
Int2 & Marketing, psychology, food & $0: 12$ & 3 \\
Int3 & Healthy food, finance & $0: 21$ & 10 \\
Int4 & Marketing, innovation & $0: 19$ & 1 \\
Int5 & Project management, general business & $0: 28$ & 3 \\
Int6 & Dentistry & $0: 35$ & 2 \\
Int7 & Service design & $0: 16$ & 2 \\
Int8 & Service design & $0: 16$ & 2 \\
Int9 & Service design, service research & $0: 32$ & 2 \\
Int10 & Services research, marketing innovation & $0: 56$ & 10 \\
Focus groups & Int1, Int2, Int3, Int4, Int6 & $2: 02$ & \\
FG1 & Int7, Int8, Int9 & $1: 41$ & \\
FG2 & &
\end{tabular}

\section{A service science} approach

443

443


JOSM 24,4

444

research, meetings with the client, and workshops and interviews with children and related stakeholders. From the value-in-use perspective, value is always experientially, uniquely, and contextually perceived and determined by the customer. Therefore, the project team asked children and teachers to share their individual experiences in their natural contexts (e.g. classroom) (Appendix 2 for the research diary and Appendix 3 for the workshop template). We gained a complete picture of the service environment by synthesizing all relevant information. The stakeholder map, presented in Appendix 4, thus represents an outcome of this stage. In the second, shape stage, the team takes all previous insights and builds on them to derive a new service concept that lives up to the needs and expectations of different stakeholders. Key deliverables of the shape stage include the developed personas (Appendix 5), customer journeys (Appendix 6) and story boards (Appendix 7). The third and final stage of the service innovation process is the factoryze stage, in which the team develops and validates the new concept by iteratively asking users and clients whether they perceive it as valuable. The structure and screenshot (Appendix 8) of the virtual communication platform for healthy food are key deliverables of this stage.

\section{Data collection}

We used two sources of data, project documents (i.e. all data produced during the KU4C project) and project reviews (i.e. individual interviews and focus groups conducted with $\mathrm{KU} 4 \mathrm{C}$ project team members). By triangulating these data, we validated our findings (Jick, 1979). We began by gathering an extensive range of project documents produced during the KU4C project, such as meeting minutes, recordings of weekly team meetings, communications among team members (through the online project management system), and intermediary findings, as well as project deliverables (e.g. stakeholder maps, customer journeys, storyboards, prototypes, final reports) (Table II; Appendices 1-8). The project documents also included insights from more than 100 children and 27

Project documents

Team communication

Continuous communication

Weekly meetings (with and without client)

Children's needs and preferences

Desk research

Workshops, in-depth interviews, observations

Stakeholder analysis

Desk research

Workshops/interviews with stakeholders

Project deliverables

Table II.

Overview of project documents
148 pages of discussion via project management system Agendas, minutes, presentation slides, meeting audio recordings

Articles from scientific and popular sources, interviews with education experts

Agendas, guide, templates, summary of findings

Related articles and studies, overview of findings Agendas, guide, templates, design tools, questions, summary of findings

Stakeholder map, personas, customer journeys, web site map, storyboard, prototype sketches, validated prototype, project report, final presentation 
stakeholders, collected during workshops, observations, and interviews, which were pivotal for understanding their interests and validating the outcomes.

Furthermore, the project reviews include interviews and post-hoc focus groups with all ten team members to review the project process and its critical success factors (Table I). To probe individual knowledge and facilitate recall, we conducted ten individual in-depth interviews during the final project week, either face-to-face or by telephone. Open-ended questions related to each interviewee's background and role in the project; then we collected information about initial expectations of the project and their experience thus far, as well as their perceptions of their own and others' contributions. With regard to the service design process, we asked about the major strengths and weaknesses associated with developing healthy food experiences. To probe collective knowledge and reflect on the project in general, we conducted two focus groups two weeks after the end of the project. Both focus groups followed the same procedure: after explaining its purpose, the moderator asked about the lessons learned about healthy food communication and its (dis)similarities with other service innovation projects. Then the participants engaged in a shared reflection about critical success factors, main challenges, and project outcomes. Both the interviews and the focus groups were recorded and transcribed, in conjunction with detailed notes.

\section{Data analysis}

We categorized the project documents as team communication, children's needs and preferences, stakeholder analysis, or project deliverables (Table II). Next, we looked for similar topics emerging in relation to the characteristics of a healthy food experience, its communication, and success factors for innovating it, which thus offered guidance for our project review with the project team members.

We performed a thematic content analysis of the transcribed interviews and focus groups with project team members, then coded, categorized, and identified principles, enablers, challenges, and outcomes of the service innovation project. The sequential order of the project review with the same respondents (interviews, then focus groups) enabled us to compare project expectations with actual outcomes, which mitigated the chances of hindsight bias (Dul and Hak, 2007). Thus, we could refine emerging themes and validate the tentatively formed relationships. Despite the qualitative nature of our research, the frequency with which framework constructs emerged may offer some direction for the next steps in the data analysis. All constructs were mentioned in the project reviews (in 17 percent to 100 percent of the 12 project reviews) and mentioned multiple times (five to 30 times) across all project reviews. Because interviews Int1-Int10 were conducted shortly before the project end, they put more emphasis on the enablers and principles; the longer focus groups FG1-FG2, which took place after project completion, took a more balanced view of all the framework constructs. We found no considerable difference between members with a service design background (Int7, Int8, Int9, FG2) and the other members, indicating the cross-team reliability of the results.

We next compared themes, constructs, and relationships against existing research involving unhealthy food, services, and innovation. This iteration between theory and data helped sharpen the construct, theoretical relationships between constructs, and underlying theoretical arguments (Eisenhardt and Graebner, 2007). During the analysis, we also extracted relevant quotations to illustrate our findings and increase our depth of understanding (Dul and Hak, 2007).
A service science approach

445 
JOSM 24,4

446

\section{Results}

The findings emerging from our analysis reflected three main insights that sequentially built on one another. First, we extracted from the empirical data distinct factors that stress the central nature of communication for healthy food experiences and confronted them with extant literature. Second, we adopted a value-in-use perspective to theoretically validate our view on healthy food experiences and demonstrate how communication influences its value-in-use. Third, we established a conceptual framework, with the project principles, enablers, challenges, and outcomes of improving the healthy food experience through better communication.

Factors determining communication for healthy food experiences

Simultaneity of functional and hedonic benefits. The project team viewed the simultaneous occurrence of both benefit dimensions as inherent to the development of communication about healthy food experiences for children. Functional benefits included balanced, sufficient nutrition intake to feel better, be less affected by diseases, and achieve better performance in physical and cognitive activities such as sports and school work. In contrast, hedonic benefits originated with both the core product and the augmented offering. For example, the online platform enhanced children's feelings of accomplishment when they were able to identify food attributes and origins, because they had adopted the role of a farmer growing and harvesting grains and vegetables. The simultaneous consideration of both benefit categories helps resolve the traditional trade-off between utilitarian and hedonic value, often seen as two extremes of one continuum (Belei et al., 2013) and focus on the overall experience. In this case, the healthy core product was augmented by fun and pleasurable elements, a scenario similar to gamification. That is, by using gaming elements in a non-gaming context, providers enable users to complete tasks, such as filling in questionnaires or learning management skills (Zicherman and Cunningham, 2011).

Influence of multiple stakeholders. The benefits are most salient for children who can be considered end consumers, but other groups also are interested in and exert considerable influence over healthy food experiences. In the immediate environment of children, we find teachers, parents, and grandparents, who seek physical well-being and enjoyment for the children in their care. At a greater distance, societal organizations such as health care providers, government organizations, industry associations, and media or non-governmental activists pay considerable attention to the well-being of children, in the hope of avoiding excessive costs for society, such as those due to chronic diseases or obesity (Livingstone, 2006). Our analysis considers the interest of stakeholders in children's well-being as an underlying baseline of typical social and economic behavior in Western societies (UNICEF, 2007). In the resulting stakeholder map (Appendix 4), the greater a group's distance from the children, the stronger its emphasis on utilitarian, financial, or long-term-oriented goals rather than hedonic ones. Communication to children needs to consider these goal conflicts among stakeholders, which appear inherent to healthy food experiences (McGinnis et al., 2006).

Our analysis also demonstrates that stakeholders can act as role models. Social norms regarding the amount or type of food consumed are conveyed by impersonal (e.g. media) and personal (e.g. peers) sources (Beuningen et al., 2009). The children in this case study developed attitudes toward healthy food by listening to friends, family, and teachers. Teachers in particular were considered reliable authority figures for choices and learning about food. Furthermore, they appeared, unlike parents, as independent, accurate sources of information and role modeling (Beuningen et al., 2009). 
For example, children carefully observed and imitated teachers' behavior, such as eating fruit during breaks, and followed their recommendation for useful web sites.

Knowledge requirements. Customers typically require a considerable amount of expertise to assess product qualities (Alba and Hutchinson, 1987). The increasing availability of health-related information, such as nutrition statements and organic labels, increases transparency but also expands the information load and level of complexity (Steenkamp, 2000). For children, initial expertise tends to be quite limited, which demands intense learning about products, their origins, and their processing. For example, on the KU4C platform, children view video clips tracing a tomato, from the seeding through its processing in the ketchup factory until its use, and by reflecting on this information, they may better self-regulate their consumption (Calvert, 2008; Geyskens et al., 2008). Consumption may occur in public or unobserved, so self-regulation rather than control by parents is more likely to prevent unhealthy consumption.

\section{Healthy food experience taking a value-in-use perspective}

Expanding on the empirical findings from the previous section, we attempt to generalize value creation through healthy food communication and strengthen its theoretical embeddedness. The holistic value-in-use approach of the service-dominant logic is useful for determining value creation in which users become better off (Grönroos, 2011) or achieve increased well-being (Vargo and Akaka, 2009). From a value-in-use perspective as presented in FP 10 (Vargo and Lusch, 2008), value is experientially, uniquely, and contextually perceived and determined by the customer.

Experiential perceptions of value-in-use result from the use or possession of resources or mental states (Grönroos, 2011). The children in our study entered the communication platform and selected activities, such as growing plants and taking the (simulated) role of a baker. This self-selection increased their sense of ownership and emotional attachment (Fuchs et al., 2010). As service designer Int8 confirmed:

The child is the starting point; it is important to encourage ownership over the activities that are done inside the website. They must have the feeling that they build their own company like a bakery.

The experience on the platform encouraged a cognitive learning process, resulting in enhanced knowledge and feelings of accomplishment, as well as improved mental states in terms of happiness and joy. The value of an offering also depends on its context, including actors, objects, and their relationships (Chandler and Vargo, 2011). The experience is embedded, in our case in the KU4C platform, and determined by communication with peers, personal information (e.g. profile, uploaded pictures of meals), or other information sources. Children may select the type of information (e.g. recipes, games) or activities (e.g. gaming, watching videos, reading, chatting with others). This empowerment increases children's feelings of self-efficacy and recognition and, ultimately, their positive assessment of the experience (Beuningen et al., 2009). Thus, communication related to the healthy food experience clearly affects the aspects of value-in-use and is essential for developing and encouraging such experiences.

Conceptual framework for improving healthy food experiences

The unique nature of the healthy food experience and its communication as explained before, also entails a specific set of enablers, principles, challenges, and outcomes in developing them (Figure 1).
A service science approach

447 
JOSM

24,4

448

\section{Figure 1.}

Conceptual framework for innovating communication about healthy food experiences

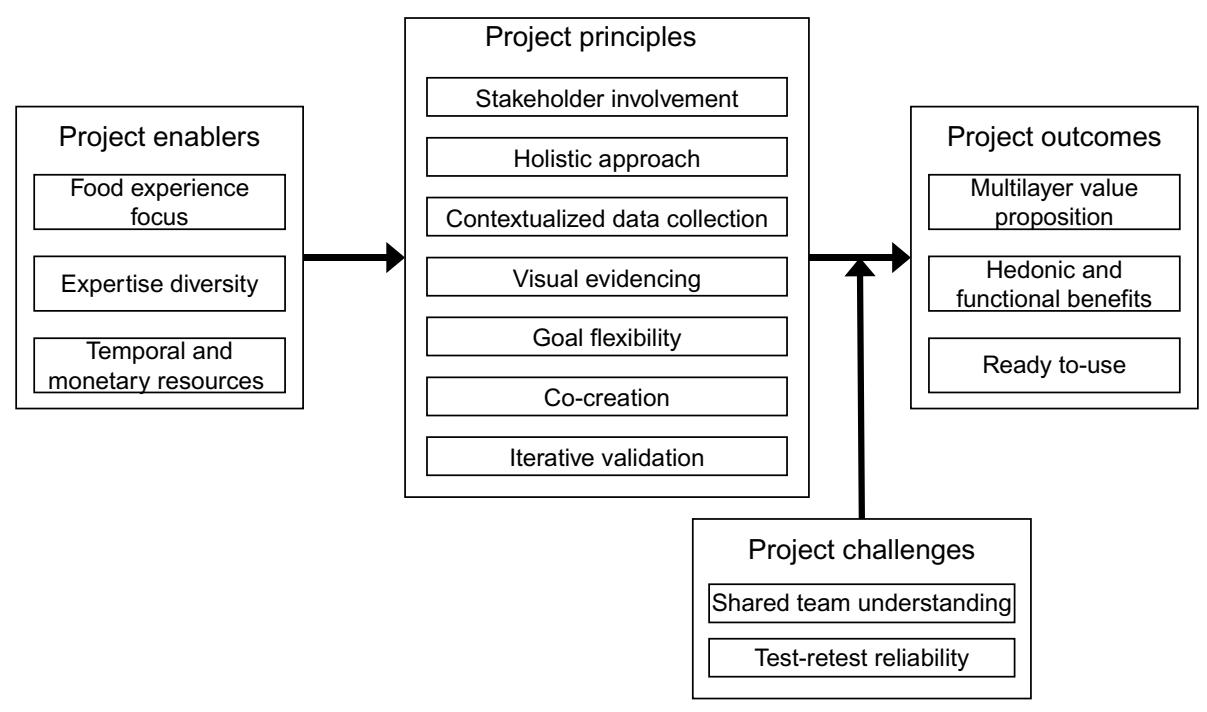

Project enablers

Several factors were critical for enabling the establishment of the innovation project KU4C.

Food experience focus. This project aimed to improve communication about healthy food experiences by serving both functional and hedonic benefits, such that a traditional focus on functional benefits shifted toward a more balanced approach. Such an experience occurs when a company intentionally uses services (e.g. online games, cooking workshops) as the stage, and goods as support (e.g. aprons, cookbook) to engage individual customers in a way that creates a memorable event ( = experience) (Pine and Gilmore, 1998). Healthy food experiences are essential for every human and therefore offer a common ground across domains of expertise and ensure that every KU4C project team member has some prior knowledge, unlike technology-driven service innovation projects. The team members' commitment increased because of the topic's relevance for society at large. Cause-related activities, such as environmental protection or fair-trade initiatives, often strengthen employees' commitment to a firm that pursues these objectives, through their stronger identification with the company's values and practices (Hoeffler et al., 2010).

Expertise diversity. The project team members of KU4C contributed expertise in a wide range of areas (Table I), which is indispensable in a service science approach. The project staffing took place after an initial analysis of project needs and the expertise present on the client side, which contributed educational, food, and business know-how. There is rich evidence of the positive effect of the interdisciplinary nature of project teams on innovation outcomes (De Brentani and Cooper, 1992; Griffin, 1997; Vermeulen, 2001), for different reasons. In our case, the holistic nature of healthy food experience that balances various perspectives, interests, and benefits demanded a wide range of complementary expertise. The KU4C project maintained its interdisciplinary nature, even for subgroups of two to four members that formed to complete 
limited tasks. Each subteam formed around members contributing expertise in the key areas, such as service design, business, food, and health.

The involvement of members with complementary skills demanded their openness to listen, discuss, and integrate different ideas. As reported during the concluding focus group meetings, the KU4C team members considered the combination of diverse expertise and open-mindedness among team members as key project enablers. Listening and reflection skills also helped them benefit from diverging thoughts and ideas in the beginning, as well as to converge on a mutual agreement and solution later (Beckman and Barry, 2007).

Temporal and monetary resources. The methodology underlying the healthy food innovation originates in the principles of service design, which is an elaborate methodology with multiple tools, but its loose boundaries also facilitate the adaption of the project focus as needed (Mager, 2009). Yet the lack of formalization and guidelines demand highly skilled project members. In the KU4C case, three trained service design experts participated; the other members had specific knowledge in other relevant domains but mixed levels of service design know-how. This situation caused a time constraint because, as service designer Int7 noted, "people often are inexperienced in service design, then you spend those meetings talking about the methods rather than progressing in your project." The application of service design tools, such as co-creation workshops with children and their parents, also demands time and financial investments. Roughly $€ 9,000(\$ 11,769)$ in direct costs could be assigned to this project, including compensation for project team members, travel expenses, and representation costs (e.g. reports, final presentations, snacks). A lack of adequate resources is a main impediment to innovation projects (De Brentani and Cooper, 1992); this hindrance is amplified with a service design approach. The total time invested in this project was $1,280 \mathrm{~h}$. Thus, time constraints resulted in the use of convenience samples (nearby schools), and monetary constraints led to a clickable HTML version of the design, rather than a fully functioning web site.

\section{Project principles}

Our case revealed several key principles that were pivotal for project execution.

Stakeholder involvement. As we wanted to consider the needs and preferences of children and other stakeholders in our service innovation project, we had to involve all these stakeholders in the project. Stakeholders with daily, personal contact with children are their parents, grandparents, and teachers; more distant stakeholders include healthcare providers, food firms, and industry association. Developing a service system requires input from multiple stakeholders (Edvardsson et al., 2011) and mechanisms to identify and resolve conflicts of interest. Stakeholders not only provided crucial information about their own perceptions and preferences but also granted consent for children's participation and financial contributions. Innovation and services marketing literature increasingly advocates the wider consideration of stakeholders to match the complexity of the development and commercialization of new offerings (Smith and Fischbacher, 2005). The stakeholder map (Appendix 4) and a need analysis offered useful starting points for identifying and categorizing stakeholders, that had to be involved, as well as mapping out their preferences and roles in the experience process.

Holistic approach. The innovation process took a comprehensive perspective on users' anticipated experience with the virtual platform, instead of focusing on single encounters. As Int4 stated:
A service science approach

449 
JOSM 24,4

\section{0}

[...] we look at the service as a whole and consider the links and effects between the user and the different touchpoints [...] to improve the elements which have an impact on the whole service experience.

The project-documented personas, customer journeys, and user observations clarified the role of KU4C and the children at each touchpoint (Stickdorn and Schneider, 2010). For example, a teacher might recommend the KU4C web site to the stereotypical child (persona) Femke. Although excited, Femke needs to convince her parents, who worry about the web site's safety and educational value, to approve her visit. During subsequent KU4C visits, she logs in, creates her personalized avatar, and engages in activities such as recipe uploading or quiz participation (Appendix 6). Understanding how customers behave across a customer journey includes assessing their feelings, history, motivations, and abilities, to ensure a more accurate picture of customer needs (Zomerdijk and Voss, 2010) and capture not just their interface with the platforms but also with other stakeholders - in Femke's case, her teacher and parents.

Contextualized data collection. Because the value of the service is always uniquely and phenomenologically determined by the beneficiary (Vargo and Lusch, 2008), the KU4C project employed service design tools to capture children's behavior in a natural environment, including research diaries to record children's food experiences, diaries to self-document internet surfing behavior, prototype testing workshops, and shadowing children as they surfed the internet (Appendices 2, 3, and 8). During the latter, children were invited to sit down at a computer and navigate through their favorite web site while observers recorded their approach, navigation skills, and preferred content. In contrast with surveys or laboratory experiments, such ethnographic techniques acknowledge a user's embeddedness in a real-life context that affects his or her assessment and behavior (Belk, 2006; Elg et al., 2012). This step was particularly useful, because children possess limited experience in completing surveys, and their responses to healthy food discussions might be prone to social desirability bias. Int9, a service designer, confirmed that contextualized data collection methods were particularly accurate, because "when working with children, indirect asking leads to superior answers and insights."

Visual evidencing. The project used a number of tools such as personas, story boards, prototypes, and process maps to visualize information (Appendices 1, 5, 7, and 8). Beyond the content, information quality also depends on its aesthetic representation (Stickdorn and Schneider, 2010). Process maps and a wall of sticky notes supported the structuring, categorizing, and relating of information to improve decision making. As service designer Int7 explained, sticky notes with:

[...] ideas on the wall make the information visual to us. Afterwards we take a step back and try to cluster this. At the end of the session, we try to build meta-categories such as education or activities, and try to link it to the interest of the personas.

Furthermore, prototype screenshots and - later in the project - an actual prototype of the web platform added realism and proof of whether it would match expectations, before the end of the project (Appendix 8). Personas, descriptions of representative users, and their customer journeys (Appendices 5 and 6) translated abstract customer segments into realistic customers and assisted in the verification of the final deliverable.

Goal flexibility. The clarity of project goals and deliverables is critical to harmonize expectations and guide project work (De Brentani and Cooper, 1992). Yet in the case of $\mathrm{KU} 4 \mathrm{C}$, only the overall project scope and objective was agreed upfront; specific goals 
and project deliverables were continuously distilled and refined. Such a flexible approach allows for adaptation to new insights and taking advantage of emerging opportunities. The initial interviews with children and stakeholders, as well as desk research on healthy food, resulted in adapted, more concrete project goals and deliverables. This increasing concretization of goals is inherent to the service science approach. The client became deeply involved and took over responsibility in the project work, but also altered the project work and goals. For example, the project team included the integration of an offline-online interface as a central requirement, because prior research had indicated its importance to increase children's engagement. Goal flexibility may lead to a greater ability to meet customer needs, but it may also demand greater team coordination and communication efforts with the client and subsequently prolong project duration (Kessler and Chakrabarti, 1999).

Co-creation. In line with, Russo-Spena and Mele (2012) we view service innovation as a process of co-creation, involving numerous stakeholders in the different stages of the new service development process. Therefore, the final consumers, children, participated throughout the project, ranging from a very active role during the data collection to a passive role during the prototype validation. Looking through the eyes of the consumer (Mager, 2009) enables the team to "come up with a better understanding of the universe of the user and can better translate what we observe. We do not try to understand everything so literally, but go further and try to add qualitative data to give the information some meaning," as project member Int4 explained. Co-creation involves the active cooperation of the project team members with the stakeholders, such as children and parents, but also cooperation among all team members and their diverse backgrounds. To illustrate, at the start of the project, two co-creation workshops, representing a core element of the project, took place at primary schools to gain deeper insights into children' eating habits, nutrition awareness, online/offline activities, and general motivations. Together, with their parents and teachers, children were invited to draw their most liked/disliked food, show their favorite web site, or guess what healthy food is. These workshop results were analyzed, interpreted, and shared among all project team members. The result was a triadic co-creation approach, in which co-creation takes place between stakeholders and team members but also among team members.

Iterative validation. The project minutes enabled validation checks of ideas, findings, and development during the project progress, with children, stakeholders, or the client, or among the project team members. The process map included several feedback loops (dotted lines) to verify, for example, the usefulness, accuracy, and completeness of the secondary research through client meeting 1 (Appendix 1). Rather than following the typical sequential innovation steps, the "stages are very parallel instead of separate. There is a lot of back and forth, we find out something new, and then try to validate it with, e.g. the interviews, to make sure that the ideas make sense to the stakeholders," according to Int5. Intermediate outcomes and elements are validated to avoid the emergence of more severe problems later. The societal relevance of healthy experience added attention to the validation, through the common sense of each project team member, before consumers, stakeholders, and clients were involved.

\section{Project challenges}

The implementation of the innovation process experienced several obstacles that challenged its successful implementation.
A service science approach

451 
JOSM 24,4

\section{2}

Shared team understanding. The team members' diverse expertise, work experience, and functional and professional backgrounds led to misunderstanding, different valence, and divergent expectations. As service designer Int8 described:

The team was so diverse, and every discipline has its own way of thinking and working. So when we [the designers] introduced new ideas, the others sometimes did not understand us. This is because we did not stand on the same ground. Some of the techniques that we considered as important, were not perceived as important by the other disciplines.

Such lack of mutual understanding may produce dissatisfaction and conflicts within the team, and jeopardize the success of innovative activities (Vermeulen, 2001), as confirmed by Int2:

Having such a creative and dynamic working environment could also back-fire, then it is necessary to take a step back and get everyone on the same ground and make sure everyone speaks the same language again to avoid a conflict.

In this vein, greater mutual exchanges, such as frequent meetings, presenting field-specific methods, and a common project dictionary, were helpful means to avoid misunderstandings.

Test-retest reliability. The difficulty of replicating the project results, even with the same data, evoked concerns about the validity of the approach. The data collection involved tools with great implementation variability, such as workshops or observations, that were highly dependent on the skills of the executer (Belk, 2006). The data analysis also was subject to condensation and filtering, which was subjective rather than based on universal reliability criteria. For example, the five developed personas were the outcome of a vast amount of data, including multiple workshops, interviews with children, and existing scientific studies. As the academic Int1 stated:

From an academic point of view, I feared that we might not have grasped all the possible information out there. As academics, you look at an exhaustive list to reach full evidence. In this project, I had the feeling that some data were picked because someone paid attention to it or because someone liked it, but there was not any specific method applied to value if this was the most important factor. This made me feel a little uncomfortable as an academic.

Service designer Int8 acknowledged this lack of repeatability and the tacitness of the design process but also argued that:

[...] the aim is not the replicability of the results, it is not so important to build the same persona as long as the information used is consistent. Then you have a tool which can be used to communicate the persona and validate.

The main value of the tools such as personas, customer journeys, or stakeholder maps thus was their illustrative aggregation of data and provision of reference points for validating intermediate and final outcomes.

\section{Project outcomes}

The KU4C project resulted in multiple improvements of healthy food experiences.

Multilayer value proposition. As different stakeholders were included in the project, the resulting project outcome also catered to the needs of the different stakeholders and can be seen as a multilayered value proposition. The virtual platform offered a value proposition that allowed for education and learning by all stakeholders. The outcomes 
of the novel communication format spread not only to a specific target group of customers (i.e. children) but also to related stakeholders' concerns and needs. For example, children's eating behavior is affected, because children acquire education about health and nutrition while experiencing joy and satisfaction with their accomplishment of an online task (Livingstone, 2006). As Int10 mentioned:

Children value the fun aspect and the achievement. They might not value the food aspect equally, it is just the context. Yet, they also value recognition and this influences their learning process on healthy food consumption. Learning about the food is more a spill-over effect from playing.

For parents and teachers, safety and the educational effects were primary benefits, yet fun and recreation for their children played an important role too. On balance, these results demonstrate the distinct benefits that customers and stakeholders draw from improved communication around healthy food experiences, in which setting better informed individuals may result in less costly public and societal policies (Belei et al., 2013; Drewnowski, 1997; Wansink, 2004; Zimmet et al., 2001). This factor is a unique characteristic of our study approach, as Int6 noted:

The data collection from the contextual interviews, workshops and diaries is the greatest value we deliver to our client, because he would probably not have considered multiple stakeholders. "Looking through the eyes of the children" and the entire field work and validation with children, parents, and teachers, make this approach very unique and is something that the client valued a lot.

That is, the platform provider gained crucial insights about its targets, stakeholders, and their decision environment, as well as their interactive role during the experience.

Hedonic and functional benefits. Complementing the focus of the food experience on functional benefits, our results show the importance of hedonic benefits for communicating about healthy food. To detect children's and stakeholders' hedonic needs, we closely followed an empathic approach (Elg et al., 2012) and thus captured hedonic needs through diaries, contextual interviews, and observations, as well as eliciting novel insights from children's natural decision contexts. Team member Int3 explained:

The diaries and co-creation workshops were insightful, because we found out more information about the target, and barriers that were hard for us to imagine. It was a way to check, contrast and confirm our ideas and assumptions.

The pivotal role of fun elements in the project outcome represents evidence of the coexistence of functional and hedonic features that underlie communication about health food experience.

This co-existence also applies to stakeholders. For instance, Int5 explained that "the parents value the edutainment part, and are happy that their children are provided a safe and entertaining webpage which aims to educate them about food." As Int7 explained the project outcome (i.e. web site prototype) during the second focus group: "We also added the factor of 'achievement' to fun, and hope it creates indirect learning." In one game of the final prototype, children pretended to be visitors to a market, where collecting and correctly naming fruits offered them credits. Tasks that neither under- nor over-challenge the player and competition with others through credits obtained are key motivators of indirect learning from games (McGinnis et al., 2006; Zicherman and Cunningham, 2011). In aggregate, our collected data provide evidence about perceived benefits for children (e.g. joy, learning
A service science approach

453 
JOSM 24,4

454 during leisure time) and parents/teachers (e.g. safety, avoidance of frustration about unethical online behavior, interactive learning by children about food, health, and other societal issues). These findings suggest that healthy food communications are not only interactive but also multidimensional, with both hedonic and functional benefits that account for decision making (Tijhuis et al., 2012).

Tangible, ready to use. The visual content displays of the data collected through workshops with both children and stakeholders, as well as mood boards by children and stakeholders, children's research diaries, story boards, summaries of scientific evidence, and the final prototype provide great value for the project and its client (Appendices 2, 3, 7, and 8; Elg et al., 2012). These tangible outcomes substantially enhance the clients' perceptions of and trust in the new communication platform. During the first focus group, one team member argued that the client "values probably most the tangible outcomes of the research, insights and background about children and the stakeholders that we generated in this project." Tangible outcomes such as the process map and personas are especially important for developing new service systems, which are often intangible in nature and hard to imagine otherwise (Belk, 2006; Patrício et al., 2008). Moreover, such outcomes are aimed to increase the client's satisfaction, because they are immediately implementable. Investment in innovating food experience may increase value perceptions through a stronger emphasis on tangible outcomes (Kenneth and Sweeney, 2007).

\section{Implications and conclusions}

Our study explores innovation from a holistic service science perspective that addresses how to improve communication to increase the success of experience-centric service innovations. To advance our understanding of this area, we reviewed extant literature on health, food, services marketing, innovation, and service design and confronted the status quo with real-life insights from a case. Our results first show that communication is central to determining healthy food experiences and, more specifically, the simultaneity of their hedonic and functional benefits, the influence of stakeholders, and knowledge requirements. Second, our case study offers evidence of the theoretical foundations of healthy food experience as value-in-use and the role of communication in these value perceptions. Finally, we identify principles, enablers, challenges, and outcomes for developing new means to communicate about healthy food experiences. The findings advance research in several ways.

\section{Theoretical implications}

First, our holistic view stresses the hedonic attributes of and influence of interactions among stakeholders on healthy food experiences; food innovation literature tends to focus on functional attributes and the food consumer instead. Our findings reveal crucial information regarding the influence of stakeholders as gate-keepers to information and finances and the conflicts between the food consumer, in our case children, and stakeholders (e.g. parents, media, doctors, teachers), as well as among these groups. Second, we use the value-in-use characteristics (experiential, unique, contextual) to address the abstract value of healthy food. This usage reflects a key premise of the service-dominant logic and demonstrates its usefulness for analyzing real decision contexts; the logic serves as an overarching perspective facilitating the link between value creation through a healthy food experience and other constructs, such as co-creation. Third, we demonstrate the usefulness of the service science 
approach for developing experience-centric service innovations. This approach reveals multiple project enablers (e.g. expertise diversity), project principles (e.g. stakeholder involvement), project challenges (e.g. shared team understanding), and project outcomes (e.g. hedonic and functional benefits) for developing them.

In summary, we take an overarching view of service science to create a basis for systematic service innovation, in line with the service-dominant logic (Maglio and Spohrer, 2008). As this article shows, the service science approach for new service development takes a holistic approach of involving the entire service system, and can be characterized by several other specific principles. In accordance with the different disciplines that have accumulated knowledge relevant to understanding a service system, we suggest expertise diversity (multidisciplinarity) as a crucial determinant of new service development, though shared understanding is one of the main challenges that results from this determinant. Similar to Russo-Spena and Mele (2012), we view service innovation as a process of co-creation, involving numerous stakeholders in the different stages of the new service development process. Contextual data collection is a key principle of the process, unlike non-contextual data collection, because the value of the service is always uniquely and phenomenologically determined by the beneficiary (Vargo and Lusch, 2008, FP10). This definition matches recent research in business economics and (food) marketing that highlights the importance of studying and controlling for the characteristics of the decision context and environmental settings, in which individual customers make decisions according to their behavioral tendencies (Loewenstein et al., 2007, 2009; Wansink et al., 2009). Consequently, we position value-in-use for the service recipient (Vargo and Lusch, 2008) as a main outcome of the new service development process within a specific decision context/environment.

Figure 2 is a reduced version of the conceptual framework which shows the elements generalizable beyond our food experience context and contributes to the growing literature on service science. We encourage service and innovation scholars to validate this model for experience-centric service innovations and test its robustness across settings.

\section{Managerial implications}

Food innovation thus far has tended to stress nutrition intake, rather than other factors that augment the product, similar to other industries that tend to view affective stimuli (e.g. brands, usability, user interfaces) as secondary, despite their determinant effects on user adoption. Managers should pay equal attention to emotional and functional value; the latter is essentially represented by the core product, while communication about the product is key to transferring emotional value and explaining product usage. Using games in a non-gaming context, or gamification, is useful for teaching about new offerings and overcoming initial adoption resistance; such new games also require a delicate balance between challenges and skills, competitive elements and users' sense of ownership (e.g. personalized avatars).

The findings also offer policy makers, service providers, and innovation managers advice on how to involve multiple stakeholders, and their distinct interests, in the development of new forms of communication. The stakeholder map serves as a starting point to identify stakeholders and their interests. Moreover, the implementation process shows several recursive steps that support the validation of the intermediate outcomes and reconciling of diverging interests. Co-creation with stakeholders, such as through workshops, is helpful, though it also requires goal flexibility and greater team
A service science approach

455 
JOSM

24,4

456

Figure 2.

A conceptual framework for service science-based new service development

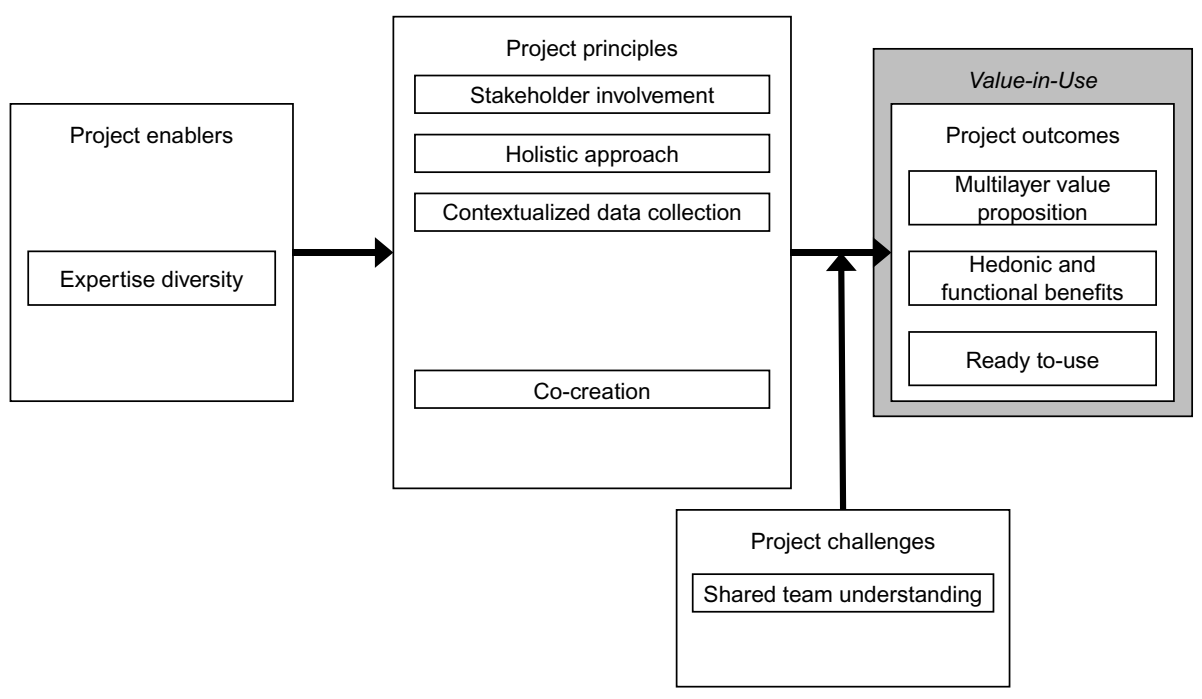

communication to accommodate new ideas. The Appendix to this article presents specific project activities to implement the elements (Appendix 9) and overcome challenges (Appendix 10), as mentioned in the framework, which may help managers conduct similar projects in the future.

\section{Further research}

The exploratory nature of this study called for a case study design, which provides an in-depth understanding of service science principles but also limits the generalizability of our findings. Further research would benefit from expanding the sample to other industries and contrasting our findings with other cases, to check the cross-disciplinary validity of the service science framework. An examination of the frequencies of the framework elements mentioned in the project reviews shows that the highest frequencies among the antecedents pertain to expertise diversity (30 times in 100 percent project reviews) and need for temporal and monetary resources (19 in 75 percent), among the principles to visual evidencing (23 in 75 percent) and co-creation (14 in 58 percent), among challenges to shared team understanding (16 in 83 percent), and among outcomes to tangible, ready to use (nine in 58 percent). These results hint at the relative importance of these elements for service development. A large-scale, quantitative investigation of service design projects could better establish the relative importance of drivers and key principles for innovation success, as well as determine industry- (e.g. importance of user involvement) and organization- (e.g. openness for service design) specific contingency effects. Comparison of the identified principles with other traditional product innovation processes also might be helpful, to determine if strong user involvement during service design hinders the development of truly new innovation (Knudsen, 2007) or if service design principles and tools overcome such barriers. Finally, research would benefit from a more profound understanding of the relationship between the emotional and functional benefits of health food experiences. Our study indicates that the development of new communication may resolve their trade-off, but experimental research probing 
alternative means of communications (e.g. food labels, cause-related advertisement, social games) and actions (e.g. experimental designs involving real consumption) would be valuable for scholars, managers, and policy makers.

\section{Note}

1. Healthy food is a plant or animal product that provides essential nutrients and energy to sustain growth, health, and life while satiating hunger. Healthy foods are usually fresh or minimally processed, naturally dense in nutrients; when eaten in moderation and in combination with other foods, they sustain human growth, repair and maintain vital processes, promote longevity, reduce disease, and strengthen and maintain the body and its functions. Healthy foods do not contain ingredients that contribute to disease or impede recovery when consumed at normal levels (http://depts.washington.edu/waaction/plan/append/g.html).

\section{References}

Alba, J.W. and Hutchinson, J.W. (1987), "Dimensions of consumer expertise", Journal of Consumer Research, Vol. 13 No. 4, pp. 411-454.

Beckman, S.L. and Barry, M. (2007), "Innovation as a learning process: embedding design thinking”, California Management Review, Vol. 50 No. 1, pp. 25-56.

Belei, N., Geyskens, K., Goukens, C., Ramanathan, S. and Lemink, J. (2013), "The best of both worlds? Effects of attribute-induced goal conflict on consumption of healthy indulgences", Journal of Marketing Research (in press).

Belk, R.W. (2006), Handbook of Qualitative Research Methods in Marketing, Edward Elgar, Northampton.

Berry, L. and Bendapudi, N. (2007), "Health care: a fertile field for service research", Journal of Service Research, Vol. 10 No. 2, pp. 111-122.

Bettman, R.J., Luce, M.F. and Payne, J.W. (1998), "Constructive consumer choice processes", Journal of Consumer Research, Vol. 25 No. 3, pp. 187-217.

Beuningen, J., van Ruyter, K., de Wetzels, M. and Streukens, S. (2009), "Customer self-efficacy in technology-based self-service: assessing between- and within-person differences", Journal of Service Research, Vol. 11 No. 4, pp. 407-428.

Calvert, S. (2008), "Children as consumers: advertising and marketing”, The Future of Children, Vol. 18 No. 1, pp. 205-234.

Chandler, J.D. and Vargo, S.L. (2011), "Contextualization and value-in-context: how context frames exchange", Marketing Theory, Vol. 11 No. 1, pp. 35-49.

Conner, M., Fitter, M. and Fletcher, W. (1999), "Snacks and stressing: a diary study of daily hassles and between-meal snacking", Psychology and Health, Vol. 4 No. 1, pp. 51-63.

Costa, A.I.A. and Jongen, W.M.F. (2006), "New insights into customer-led food product development", Trends in Food Science \& Technology, Vol. 17 No. 8, pp. 457-465.

Cullen, K.W., Baranowski, T., Rittenberry, L., Cosart, C., Hebert, D. and de Moor, C. (2001), "Child-reported family and peer influences on fruit, juice and vegetable consumption: reliability and validity of measures", Health Education Research, Vol. 16, pp. 187-200.

De Brentani, U. and Cooper, R.G. (1992), "Developing successful new financial services for businesses”, Industrial Marketing Management, Vol. 21 No. 3, pp. 231-241.

Dhar, R. and Wertenbroch, K. (2000), "Consumer choice between hedonic and utilitarian goods", Journal of Marketing Research, Vol. 1, pp. 60-71.

Drewnowski, A. (1997), “Taste preferences and food intake”, Annual Review of Nutrition, Vol. 17, pp. 237-253.
A service science approach 
JOSM 24,4
Dul, J. and Hak, T. (2007), Case Study Methodology in Business Research, Butterworth-Heinemann, Oxford.

Edvardsson, B., Ng, G., Zhi Min, C., Firth, R. and Yi, D. (2011), "Does service-dominant design result in a better service system?”, Journal of Service Management, Vol. 22 No. 4, pp. 540-556.

Eisenhardt, K.M. and Graebner, M.E. (2007), "Theory building from cases: opportunities and challenges”, Academy of Management Journal, Vol. 50 No. 1, pp. 25-32.

Elg, M., Engström, J., Witell, L. and Poksinska, B. (2012), “Co-creation and learning in health-care service development”, Journal of Service Management, Vol. 23 No. 3, pp. 328-343.

Flegal, K.M., Carroll, M.D., Ogden, C.L. and Curtin, L.R. (2010), "Prevalence and trends in obesity among US adults, 1999-2008”, Journal of the American Medical Association, Vol. 303 No. 3, pp. 235-241.

Francis, M., Dorrington, P. and Hines, P. (2008), "Supplier led new product development process improvement in the UK fast moving consumer goods industry", International Journal of Innovation Management, Vol. 12 No. 2, pp. 195-222.

Fuchs, C., Prandelli, E. and Schreier, M. (2010), "The psychological effects of empowerment strategies on consumers' product demand", Journal of Marketing, Vol. 74 No. 1, pp. 65-79.

Fudenberg, D. and Levine, D.K. (2006), "A dual-self model of impulse control”, American Economic Review, Vol. 96 No. 5, pp. 1449-1476.

Geyskens, K., Dewitte, S., Pandelaere, M. and Warlop, L. (2008), "Tempt me just a little bit more: effect of food temptation actionability on goal activation and subsequent consumption", Journal of Consumer Research, Vol. 35 No. 4, pp. 600-610.

Glaser, B.G. and Strauss, A.L. (1967), The Discovery of Grounded Theory: Strategies for Qualitative Research, Aldine de Gruyter, New York, NY.

Griffin, A. (1997), "The effect of project and process characteristics on product development cycle time", Journal of Marketing Research, Vol. 34 No. 1, pp. 24-35.

Grönroos, C. (2011), "Value co-creation in service logic: a critical analysis", Marketing Theory, Vol. 11 No. 3, pp. 279-301.

Grunert, K.G., Harmsen, H., Meulenberg, M.T.G. and Trail, W.B. (1997), "Innovation in the food industry: a revised framework", in Trail, W.B. and Grunert, K.G. (Eds), Product and Process Innovation in the Food Industry, Blackie Academic and Professional, London, pp. 213-226.

Helkkula, A., Kelleher, C. and Pihlstrom, M. (2012), "Characterizing value as an experience: implications for service researchers and managers", Journal of Service Research, Vol. 15 No. 1, pp. 59-75.

Hoeffler, S., Bloom, P.N. and Keller, K.L. (2010), "Understanding stakeholder responses to corporate citizenship initiatives: managerial guidelines and research directions", Public Policy \& Marketing, Vol. 29 No. 1, pp. 78-88.

Holbrook, M.B. and Hirschman, E.C. (1982), "The experiential aspects of consumption: consumer fantasies, feelings, and fun”, Journal of Consumer Research, Vol. 2, pp. 132-140.

Hult, G.T.M., Mena, J.A., Ferrell, O.C. and Ferrell, L. (2011), "Stakeholder marketing: a definition and conceptual framework", Academy of Marketing Science Review, Vol. 1 No. 1, pp. 44-55.

Jick, T.D. (1979), "Mixing qualitative and quantitative methods: triangulation in action", Administrative Science Quarterly, Vol. 24 No. 4, pp. 602-611.

Kalogeras, N., Vlachovska, S., Baourakis, G. and Kalaitzis, P. (2009), "Dutch consumers' willingness to pay for organic olive oil”, International Journal of Food and Agribusiness Marketing, Vol. 21 No. 4, pp. 286-311. 
Kenneth, B.Y. and Sweeney, J.C. (2007), "Zone-of-tolerance moderates the service quality-outcome relationship", Journal of Services Marketing, Vol. 21 No. 2, pp. 137-148.

Kessler, E.H. and Chakrabarti, A.K. (1999), "Speeding up the pace of new product development", Journal of Product Innovation Management, Vol. 16 No. 3, pp. 231-247.

Knudsen, M.P. (2007), "The relative importance of interfirm relationships and knowledge transfer for new product development success", Journal of Product Innovation Management, Vol. 24 No. 2, pp. 117-138.

Korsmeyer, C. (2005), The Taste Culture Reader, Experiencing Food and Drink, Berg Publishers, Oxford.

Krider, R.E., Priya, R. and Aradhna, K. (2001), "Pizzas: $\pi$ or square? Psychophysical biases in area comparisons", Marketing Science, Vol. 20 No. 4, pp. 405-425.

Livingstone, S. (2006), "Does TV advertising make children fat? What the evidence tells us?", Public Research Policy, Vol. 13 No. 1, pp. 54-61.

Loewenstein, G., Brennan, T. and Volpp, K.G. (2007), “Asymmetric paternalism to improve health behaviors", Journal of the American Medical Association, Vol. 298 No. 20, pp. 2415-2417.

Loewenstein, G., Downs, J. and Wisdom, J. (2009), "Strategies for promoting healthier food choices", American Economic Review, Vol. 99 No. 2, pp. 159-164.

Lusch, R.F. and Vargo, S.L. (2006), The Service-Dominant Logic of Marketing: Dialog, Debate, and Directions, M.E. Sharpe, Armonk, NY.

McColl-Kennedy, J.R., Vargo, S.L., Dagger, S.T., Sweeny, J.C. and van Kasteren, Y. (2012), "Health care customer value co-creation practice styles", Journal of Service Research, Vol. 15 No. 4, pp. 370-389.

McGinnis, M.J., Cootman, J.A. and Kraak, V.I. (2006), Food Marketing to Children and Youth: Threat or Opportunity?, The National Academies Press, Washington, DC.

Mager, B. (2009), "Service design as an emerging field", in Miettinen, S. and Kivisto, M. (Eds), Designing Services with Innovative Methods, Helsinki University of Art and Design, Helsinki.

Maglio, P. and Spohrer, J. (2008), "Fundamentals of service science", Journal of the Academy of Marketing Science, Vol. 36 No. 1, pp. 18-20.

Michel, S., Stephen, W., Brown, S.W. and Gallan, A.S. (2008), "An expanded and strategic view of discontinuous innovations: deploying a service-dominant logic", Journal of the Academy of Marketing Science, Vol. 36 No. 1, pp. 54-66.

Newman, E., O' Connor, D.B. and Conner, M. (2008), “Attentional biases for food stimuli in external eaters: possible mechanism for stress-induced eating?”, Appetite, Vol. 50 No. 1, pp. 339-342.

Ostrom, A.L., Bitner, M.J., Brown, S.W., Burkhard, K.A., Goul, M., Smith-Daniels, V., Demirkan, H. and Rabinovich, E. (2010), "Moving forward and making a difference: research priorities for the science of service", Journal of Service Research, Vol. 13 No. 1, pp. 4-36.

Palmatier, R.W., Scheer, L.K. and Steenkamp, E.M.J-B. (2007), "Customer loyalty to whom? Managing the benefits and risks of salesperson-owned loyalty", Journal of Marketing Research, Vol. 19 No. 2, pp. 185-199.

Papies, E., Stroebe, W. and Aarts, H. (2007), "Pleasure in the mind: restrained eating and spontaneous hedonic thoughts about food", Journal of Experimental Social Psychology, Vol. 43 No. 5, pp. 810-817.

Patrício, L., Fisk, R.P. and Falcão e Cunha, J. (2008), "Designing multi-face service experiences", Journal of Service Research, Vol. 10 No. 4, pp. 318-334.

\section{A service science approach}

459 
JOSM 24,4
Peck, J. and Childers, T.L. (2003), "To have and to hold: the influence of haptic information on product judgments", Journal of Marketing, Vol. 67 No. 2, pp. 35-48.

Pennings, J.M.E., Garcia, P. and Hendrix, E. (2005), "Towards a theory of revealed economic behavior", Journal of Bioeconomics, Vol. 7 No. 2, pp. 113-127.

Pine, B.J. and Gilmore, J.H. (1998), "Welcome to the experience economy", Harvard Business Review, July-August, pp. 97-105.

Raghunathan, R., Walker Naylon, R. and Hoyer, W.D. (2006), "The unhealthy = tasty intuition and its effects on taste inferences, enjoyment, and choice of food products", Journal of Marketing, Vol. 70 No. 4, pp. 170-184.

Russo-Spena, T. and Mele, C. (2012), "Five Co-s in innovating: a practice-based view", Journal of Service Management, Vol. 23 No. 4, pp. 527-553.

Shiv, B. and Fedorikhin, A. (1999), "Heart and mind in conflict: the interplay of affect and cognition in consumer decision making", Journal of Consumer Research, Vol. 26 No. 3, pp. 689-699.

Smith, A.M. and Fischbacher, M. (2005), "New service development: a stakeholder perspective", European Journal of Marketing, Vol. 39 Nos 9/10, pp. 1025-1048.

Steenkamp, J-B.E.M. (2000), "Dynamics in consumer behavior with respect to agricultural and food products”, in Wierenga, B., Van Tilburg, A., Grunert, K., Steenkamp, J-B.E.M. and Wedel, M. (Eds), Agricultural Marketing and Consumer Behavior in a Changing World, Kluwer, Norwell, MA, pp. 143-188.

Stickdorn, M. and Schneider, J. (2010), This is Service Design Thinking, BIS Publishers, Amsterdam.

Storey, C. and Easingwood, C.J. (1998), "The augmented service offering: a conceptualization and study of its impact on new service success", Journal of Product Innovation Management, Vol. 15 No. 4, pp. 335-351.

Teachman, B.A., Smith-Janik, S.B. and Sapoito, J. (2007), "Information processing biases and panic disorder: relationships among cognitive and symptom measures", Behaviour Research and Therapy, Vol. 45 No. 4, pp. 1791-1811.

Tijhuis, M.J., De Jong, N., Pohjola, M.V., Gunnlaugsdóttir, H., Hendriksen, M., Hoekstra, J., Holm, F., Kalogeras, N., Leino, O., Van Leeuwen, F.X.R., Luteijn, J.M., Magnússon, S.H., Odekerken-Schroeder, G., Rompelberg, C., Tuomisto, J.T., Ueland, Ø., White, B.C. and Verhagen, H. (2012), "State of the art in benefit risk analysis: food and nutrition", Food \& Chemical Toxicology, Vol. 50 No. 1, pp. 5-25.

Trail, W.B. and Meulenberg, M.T.G. (2002), "Innovation in the food industry", Agribusiness: An International Journal, Vol. 18 No. 1, pp. 1-21.

UNICEF (2007), An Overview of Child Well-being in Rich Countries, Innocenti Report Card 7, UNICEF Innocenti Research Centre, Florence.

van Ittersum, K. and Wansink, B. (2013), "Plate size and color suggestibility: the Delboeuf illusion's bias on serving and eating behavior", Journal of Consumer Research, Vol. 39 No. 3 (in press).

Vargo, S.L. and Akaka, M.A. (2009), "Service-dominant logic as a foundation for service science: clarifications”, Service Science, Vol. 1 No. 1, pp. 32-41.

Vargo, S.L. and Lusch, R.F. (2008), "Service-dominant logic: continuing the evolution”, Journal of the Academy of Marketing Science, Vol. 36 No. 1, pp. 1-10.

Verbeke, W., Scholderer, J. and Lähteenmäki, L. (2009), "Consumer appeal of nutrition and health claims in three existing product concepts", Appetite, Vol. 52 No. 3, pp. 684-692.

Vermeulen, P.A.M. (2001), Organizing Product Innovation in Financial Services, University Press, Nijmegen, NL. 
Wansink, B. (2004), Marketing Nutrition, University of Illinois Press, Chicago, IL.

Wansink, B., Just, D.R. and Payne, C.R. (2009), "Mindless eating and healthy heuristics for the irrational", American Economic Review, Vol. 99 No. 2, pp. 165-169.

Wansink, B., Shimizu, M. and Camps, G. (2013), "What would Batman eat? Priming children to make healthier fast food choices", International Journal of Pediatric Obesity (in press).

Ward, A. and Mann, T. (2000), "Don’t mind if i do: disinhibited eating under cognitive load”, Journal of Personality and Social Psychology, Vol. 78 No. 4, pp. 753-763.

Wimmer, V. (2012), "Service design processes and practices - a case-study approach to an interdisciplinary and customer-centric innovation method", unpublished Master thesis, Maastricht University, Maastricht, The Netherlands.

Winter Falk, L., Sobal, J., Bisogni, A., Conors, M. and Devine, C.M. (2001), "Managing healthy eating: definitions, classifications, and strategies", Health Education \& Behavior, Vol. 28 No. 4, pp. 425-439.

Yin, R.K. (2008), Case Study Research, Design and Methods, Sage, Thousand Oaks, CA.

Zicherman, G. and Cunningham, G. (2011), Gamification by Design, O’Reilly Media, Sebastopal, CA.

Zimmet, P., Alberti, K.G. and Shaw, J. (2001), "Global and societal implications of the diabetes epidemic", Nature, Vol. 414, pp. 782-787.

Zomerdijk, L. and Voss, C.A. (2010), "Service design for experience-centric services", Journal of Service Research, Vol. 13 No. 1, pp. 67-82.

\section{Appendix 1}

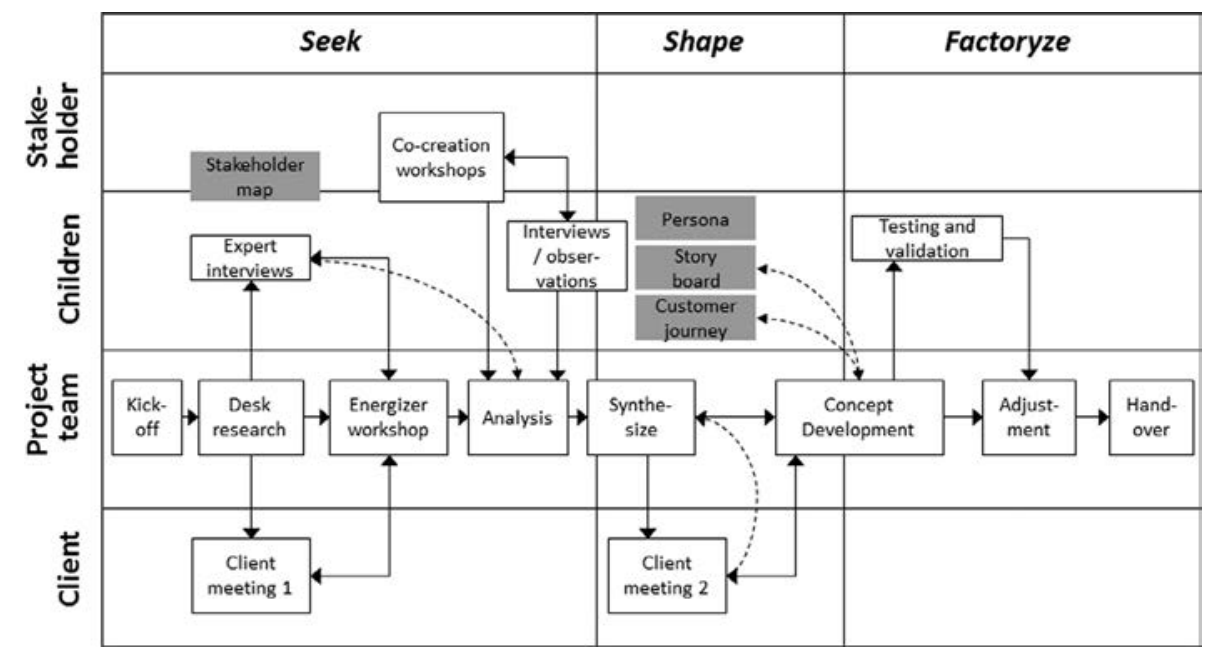

Source: Adapted from Wimmer (2012)

\section{A service science} approach

461
Figure A1. Process map 
JOSM

24,4

462

Figure A2.

Research diaries

\section{Appendix 2}

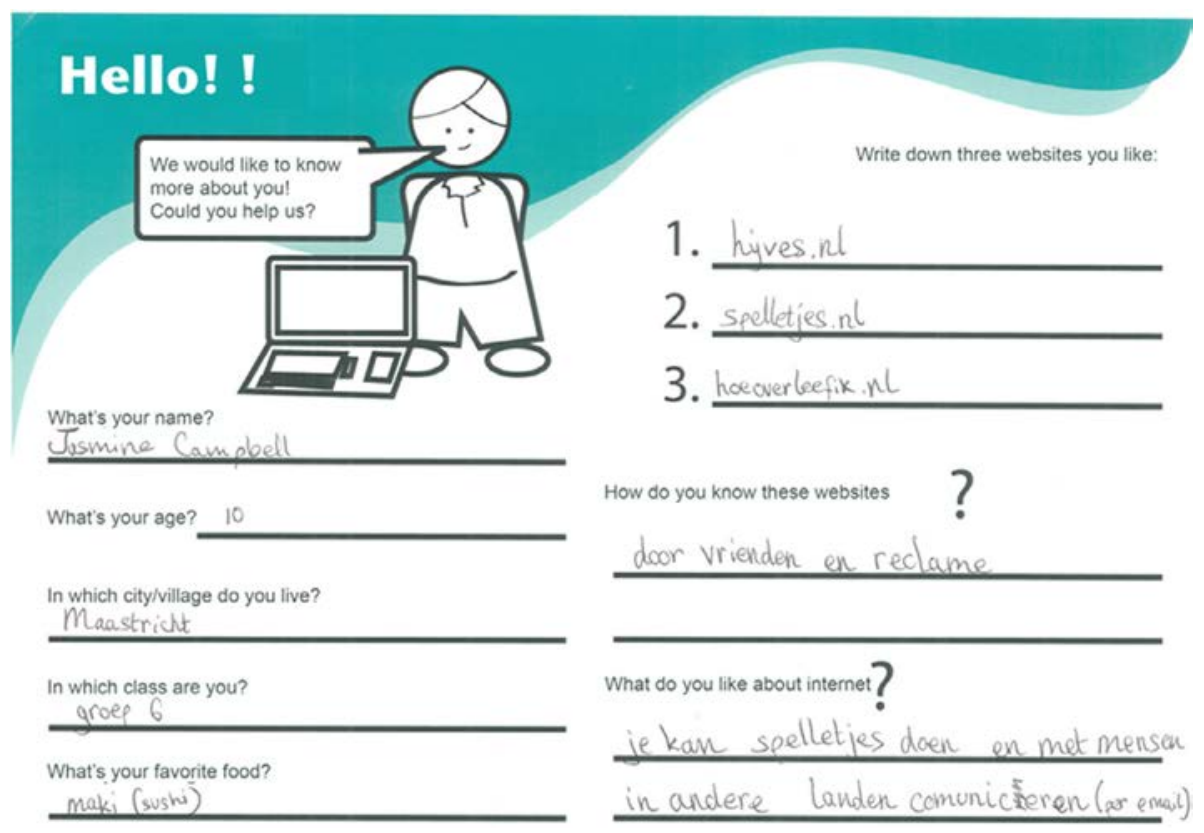

When are you most active on the internet? Circle the correct answer
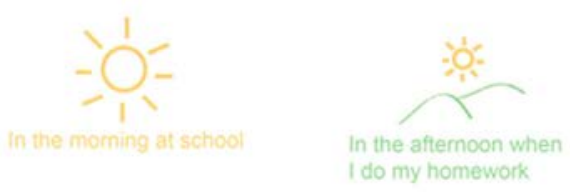

What do you like most on the internet? Tick the box you like most

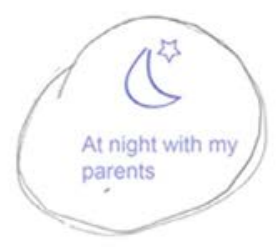

$X$ Games

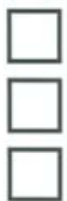

Video's / music

Chatting

Doing homework

Other

\section{Thank you!} television show?

treu jackson
What's your favorite
Figure A3. 


\section{Appendix 3}

\section{Kids \& Food: Instructions}

Participants: Ki
Material: printe
Warm-upactive
Game to get ki
Designa bo
Ask kids to cre

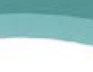

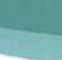

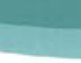

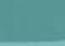

s, SSF Moderator, other SSF staff take video \& photo

(ids'Table Mat Templates (A3 color), color pencils, color papers, scissors, glue
A service science approach

463
Figure A4. Workshop templates (probes)

Ask kids to tell about what they draw. Listen carefully, make them feel confident and encourage their ideas. Make questions about their stories to gather information about their food habits and preferences.

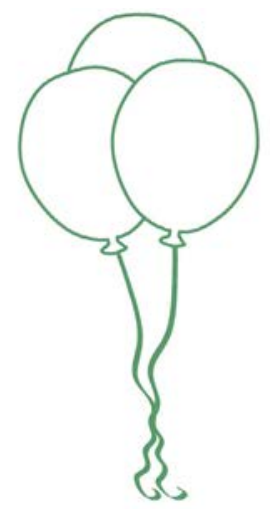

"Your best friend is celebrating her birthday. She asked you to think of food that everybody loves, to serve at the party."

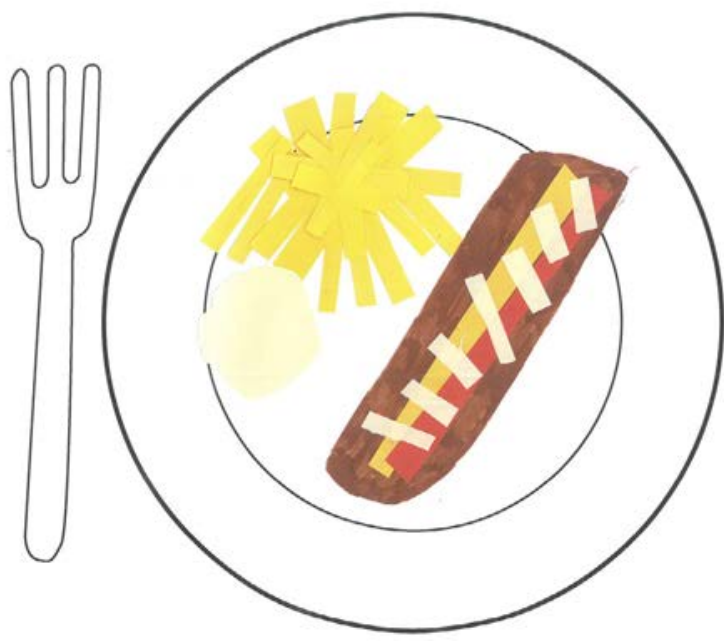


JOSM

Appendix 4

24,4

464

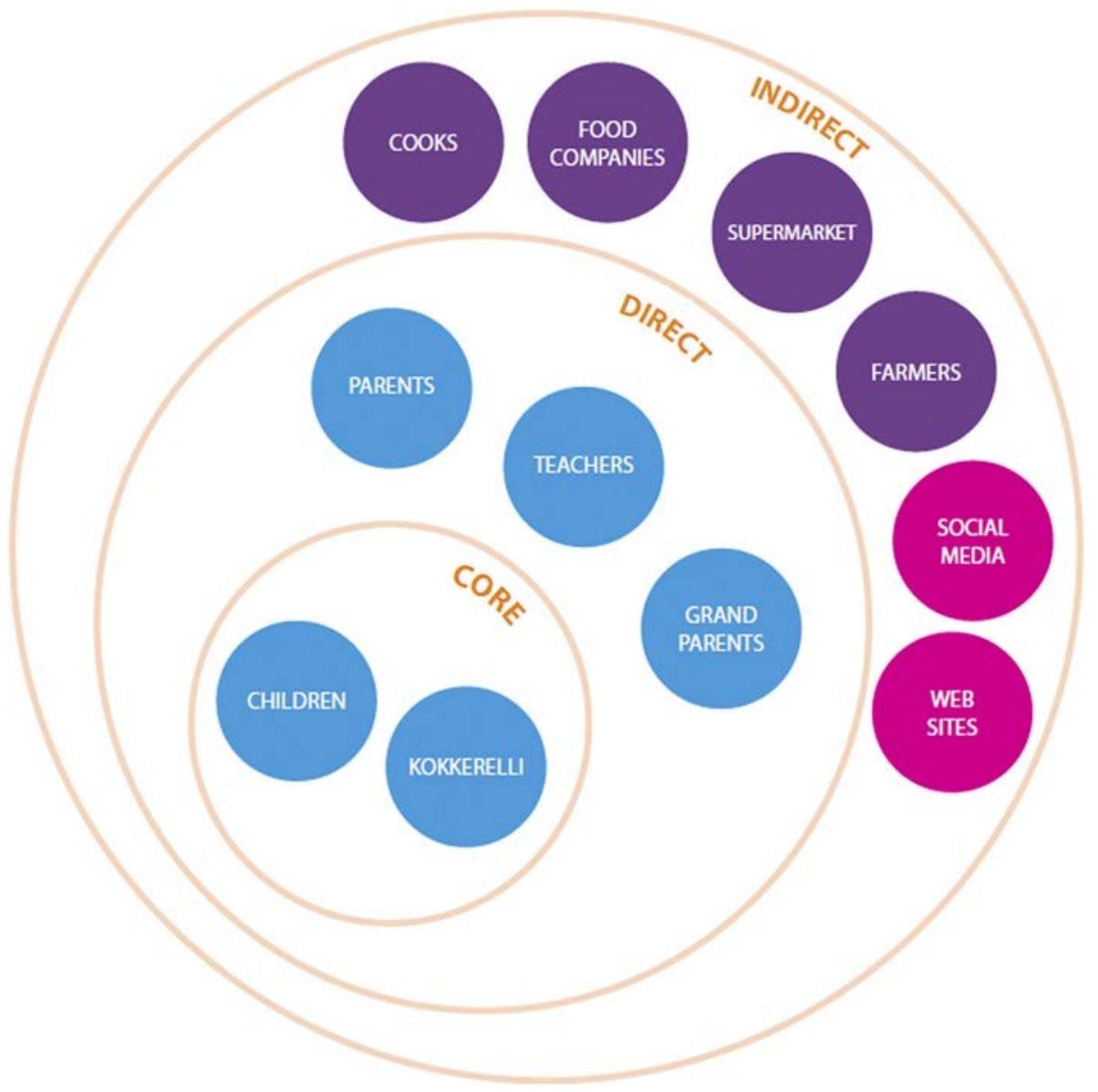

Figure A6.

Stakeholder map 

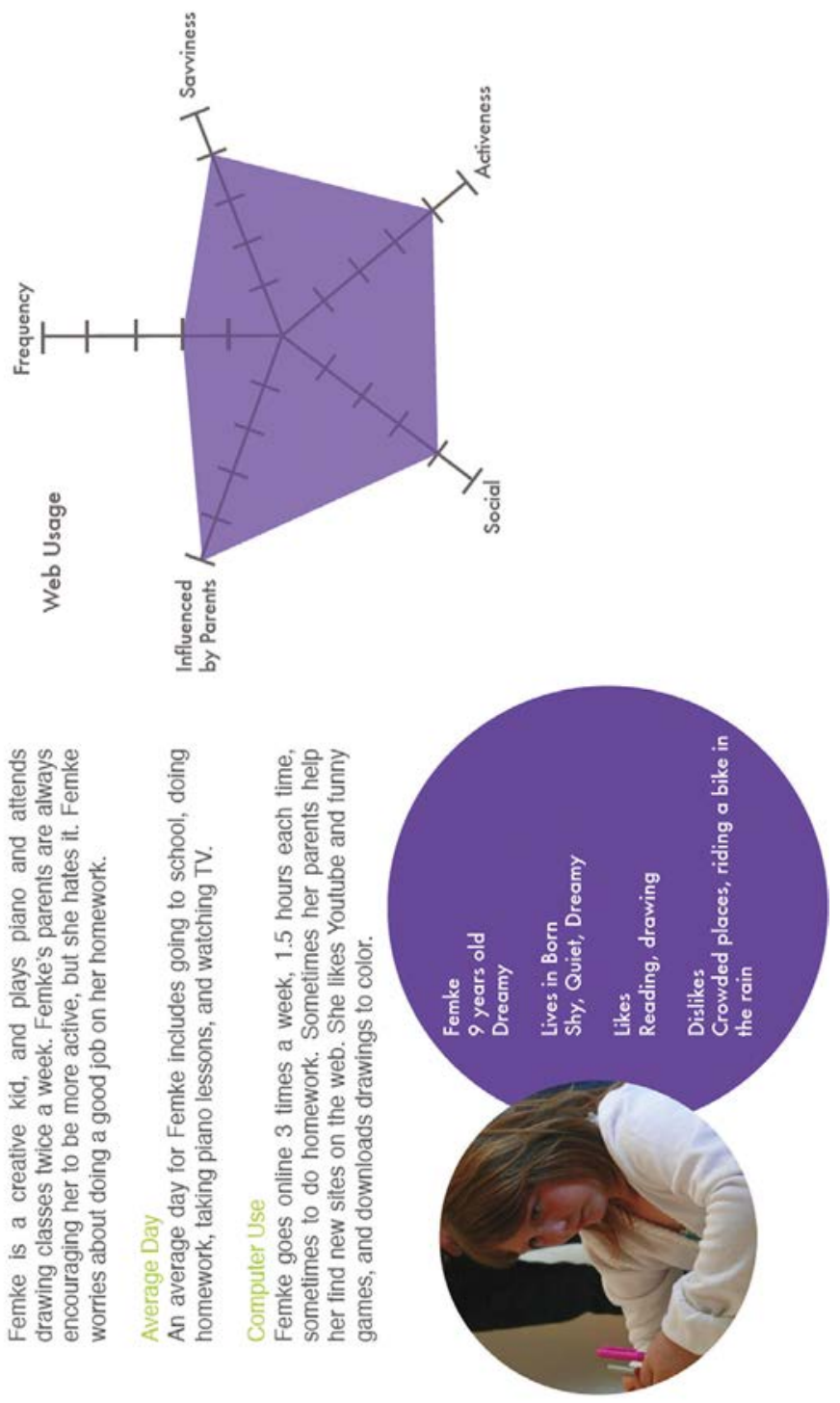

Figure A7. 
JOSM

24,4

\section{6}

Figure A8.

Femke's customer journey

\section{Appendix 6}

\section{Customer Journey map: Dreamy Femke}

1 Getting

to know

the service

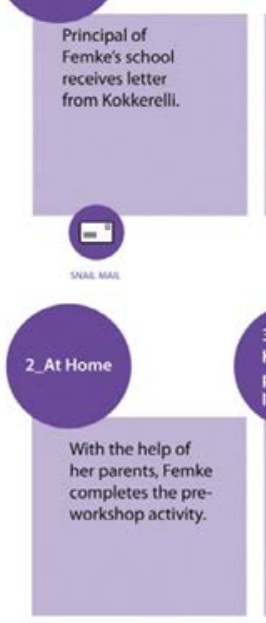

Kokkerelli

Representative calls

school principal for

appointment.

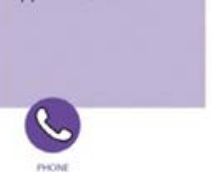

mose

3. At

Kokkerelli

physical

location

Femke and her class

participate in the

activities, and then

everyone presents

their work.
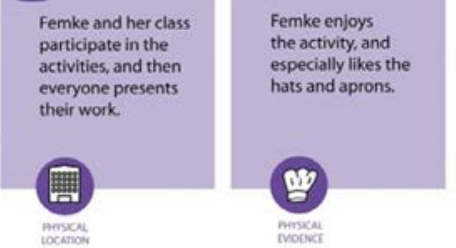

Kokkerelli Teacher

introduces kids

to the website,

and guides them

through it.

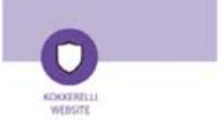

Femke tells her

parents about the

workshop, shows

them the hat and

apron, and mentions

the website.

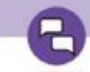

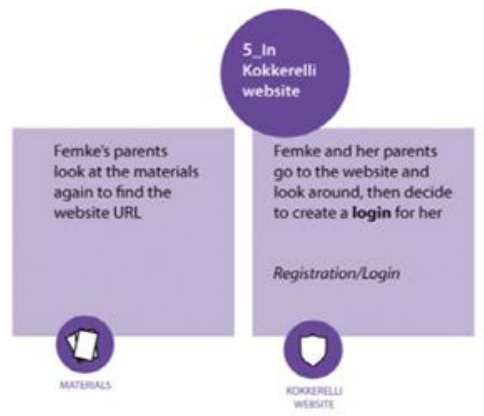

Femke starts to use own, she creates a name and avatar for herself.

Avatar/Personalization the website on he of the offline activities on the website (i.e. drawings)

Offline Activities
Femke then tries one
She uploads her drawings, and gets some "likes" from other users.

Community (Sharing Photos, Drawings)
Femke is really engaged with the offline activity social community aspect of the site, and she shares her activities with her parents.

Community (Share With Parents Button]
Femke's parents then get automated email updates on her activities.

Email Updotes on Child's Activities
Parents go to Parents page of the site

and find out about a downloadable iPhone app.

Parents Page
They download the app so that Fernke can use it during family trips.

Mobile App

Figure A9. 
Appendix 7

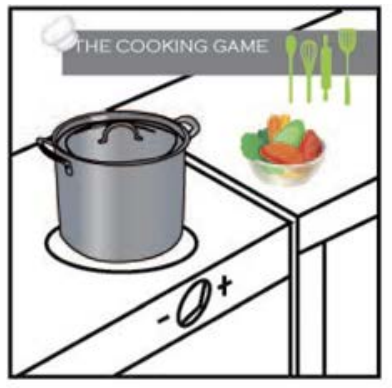

Mark decides to join the cooking

game.

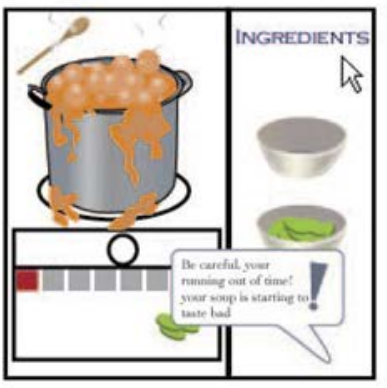

He needs to be precise on time, otherwise the soup doesn't taste good.

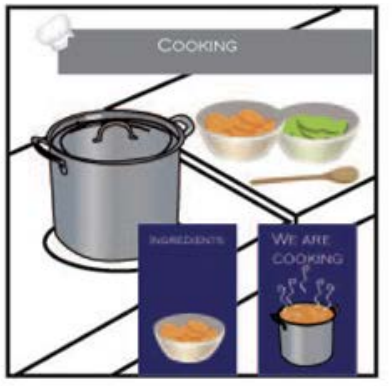

He sees all the ingredients ready to start

cooking, the stove, the pan and the wooden

spoon.

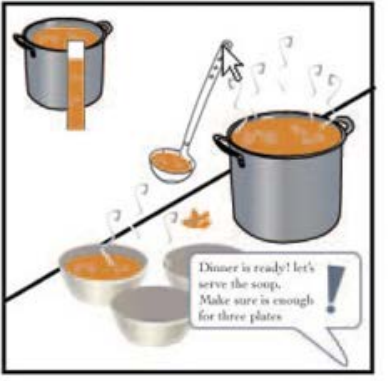

He serves the soup taking care all the portions have the same amount
A service science approach

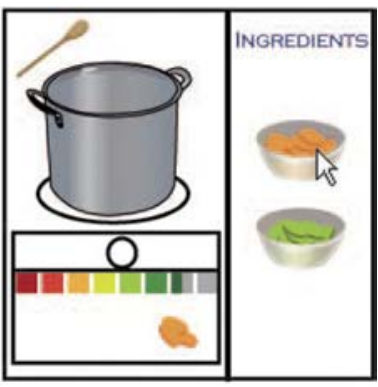

He needs to put all the ingredients step by step in the pan. The stove has a timer which indicates when he has to add ingredients.
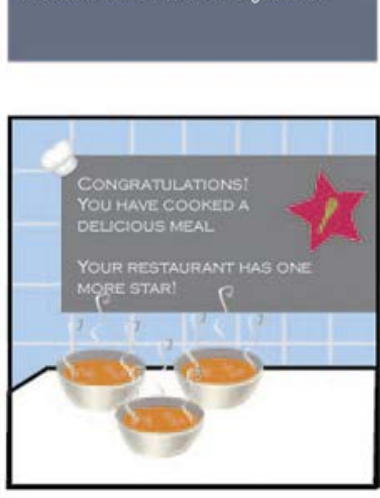

Soup is ready!
Figure A10.

Storyboard of the cooking game 
JOSM

24,4

\section{8}

Figure A11.

Prototype

\section{Appendix 8}

15

\section{Games}

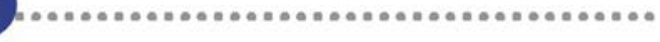

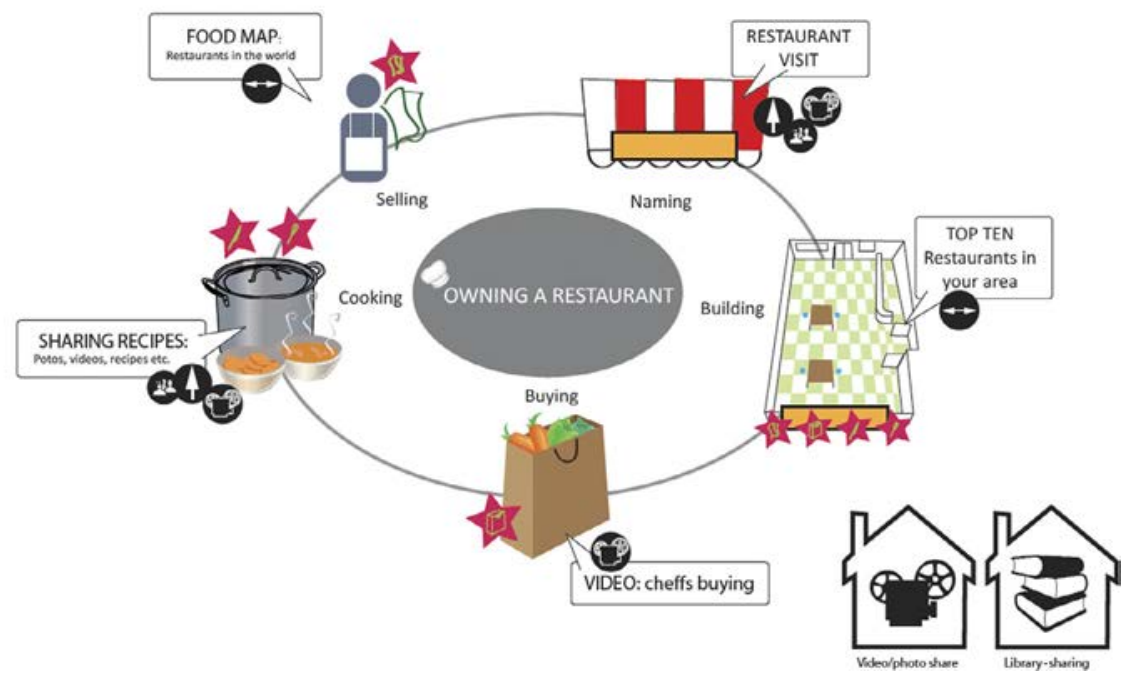

Figure A12.

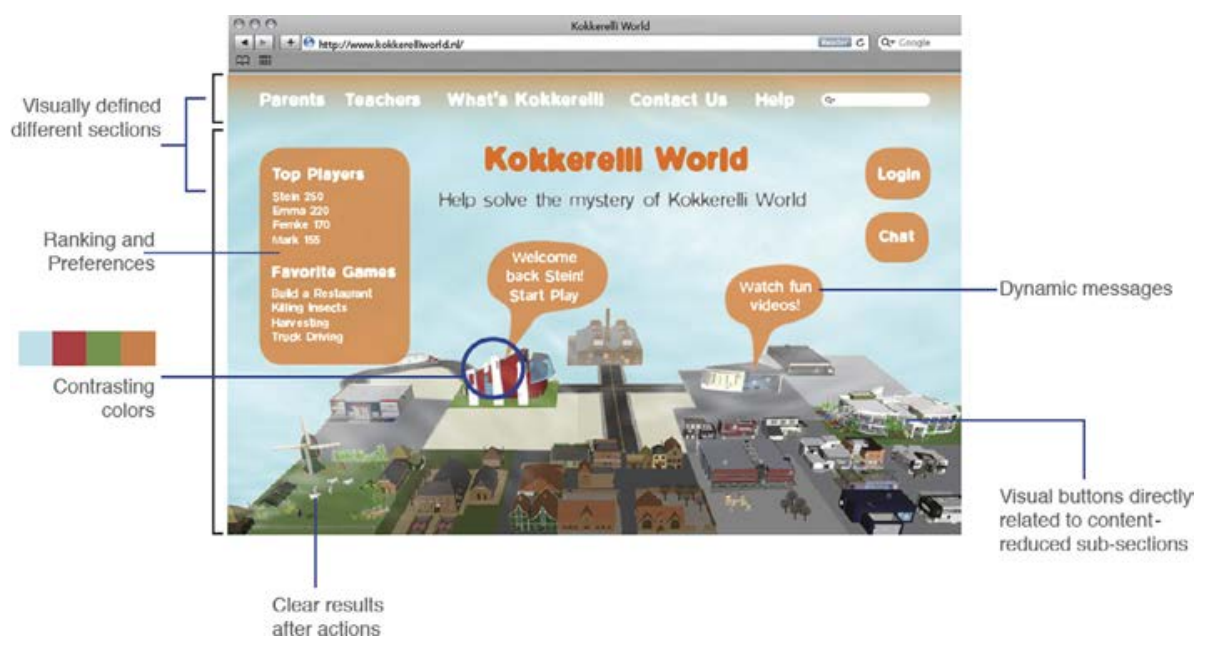


Principles

Stakeholder involvement

Holistic approach

Contextualized data collection

Visual evidencing

Goal flexibility

User co-creation
Activities

Establish stakeholder map with all stakeholders (e.g. parents, healthcare providers, food producers) including their relationship with the children (social distance in terms of contact frequency, intimacy) (Appendix 2)

Record stakeholder's motivational structure through desk research/interviews and discover conflicts of interest

Conduct a workshop and a survey to understand expertise (food- and computerrelated) and interest of parents, grandparents, and teachers as children's main gatekeepers and influencers for accessing the healthy food experience (offline and online) in the seek phase of the project (Appendix 1)

Build customer journeys to clarify role of the new communication platform and the children at the interface with the healthy food experience; the customer journey includes multiple layers: description of each touchpoint, feelings/thoughts, obstacles, influencing stakeholders, specific web site features (Appendix 4)

Compile and analyze existing research (scientific, press) pertaining to food, health, learning and children, and review industry practice/standards, nutrition standards, advertising rules for target group

Review best practices from competitors, outside the own industry and other countries to position own offer

Use observation and ethnographic techniques such as shadowing children surfing the internet, ask for feedback on a prototype and its elements (colors, features) (Appendix 8)

Conduct interviews with indirect questions about food preference (e.g. "if you cooked for your favorite music star, what would you cook and what are the ingredients?") Develop mood boards to communicate web site features to project team and stakeholders

Employ typical service design tools such as research diaries to record children's food experience and self-document internet surfing behavior

Use process maps (with stages), issue cards, and sticky note walls to structure, categorize, relate, and summarize information to improve team decision making (Appendix 1)

Visualize information and add realism through personas, story boards, and design probes to aid communication across stakeholders (Appendices 3, 4 and 7)

Develop prototypes (first screenshots and sitemaps, then actual prototypes) to visualize the deliverable and check whether it matches expectations, before the project end (Appendix 8)

Build and visualize chain linking value and web site characteristics to prove value creation of new communication

Agree on the overall project scope, vision, and general objectives upfront with KU4C while preparing for client concretization during the project

Involve KU4C employees during the entire project as regular members in team meetings and communication

Dedicate specific team tasks to KU4C employees to increase their ownership of project results

Continuously communicate with KU4C client about progress and current results, to obtain feedback, as well as to concretize and potentially adapt goals

Involve children throughout the project, from data collection to prototype validation Conduct co-creation workshops at primary schools to gain deeper insights into
Table AI.

Activities related to principles
469

(continued) 


\section{JOSM 24,4}

Iterative validation

\section{Activities}

children's eating habits, nutrition awareness, online/offline activities, and general motivations. Together with parents and teachers, have children draw their most liked/disliked food, show their favorite web site, or guess what healthy food is Analyze, interpret and share the workshop results among all project team members Employ a variety of interactive tools such as diaries, design probes, storytelling, drawing templates for web sites, and games to gather different perspectives of children (Appendices 3-6)

Conduct workshops and interviews with children and other stakeholders of the healthy food experience to continuously validate the intermediate and partial results. For example, children provide separate feedback on color, aesthetics, avatars, and webpage layout (Appendix 8)

Use the validation result as evidence of the usefulness of the developed communication platform

Validate project status and outcomes with KU4C employees and management; if necessary, feedback loops may lead to a step back (as indicated in the process map in Appendix 1)

Include validation checks against prior information (from experts, stakeholders, literature, $\mathrm{KU} 4 \mathrm{C}$ employees) to ensure that no important information is left out

\section{Table AI.}

\section{Appendix 10}

\begin{tabular}{|c|c|}
\hline Challenges & Activities \\
\hline $\begin{array}{l}\text { Shared team } \\
\text { understanding }\end{array}$ & $\begin{array}{l}\text { Before the project starts } \\
\text { Recruit team members with an open mindset, willing to learn } \\
\text { Develop direct communication modes for clarifying field-specific notions and } \\
\text { concepts (via telephone, emailing, online platforms, social media, digital media) } \\
\text { Enable sharing of information (academic articles, public policy reports, description } \\
\text { of field-specific methods and research frameworks, results) about field-specific } \\
\text { methods and concepts via the use of an intranet system (Basecamp in our case) } \\
\text { Enable the sending of direct e-mail notifications and updates about any progress } \\
\text { step via the intranet (Basecamp) } \\
\text { During the project } \\
\text { Share the objective and process of the project with all team members } \\
\text { Foster continuous interactions via intranet } \\
\text { Schedule frequent meetings with all project team members, including client } \\
\text { Facilitate regular interdisciplinary co-creation in subteams } \\
\text { Organize regular evaluation and progress meetings with all team members }\end{array}$ \\
\hline $\begin{array}{l}\text { Test-retest } \\
\text { reliability }\end{array}$ & $\begin{array}{l}\text { Accept that test-retest reliability is not the major aim of an innovative process } \\
\text { Share the objective and process of the project with all team members } \\
\text { File the different steps in the research process carefully } \\
\text { Define (and redefine if necessary) important notions and research steps consistently } \\
\text { through frequent face-to-face meetings } \\
\text { Use multiple data gathering tools and samples to test robustness of the results } \\
\text { Compare results with existing academic work and business practices } \\
\text { Collect weekly feedback from the client and end-user about the face validity of the } \\
\text { results }\end{array}$ \\
\hline
\end{tabular}

Table AII.

Activities related to key challenges 


\section{About the authors}

Dominik Mahr is an Assistant Professor at the Department of Marketing and Supply Chain Management of the School of Business and Economics, Maastricht University. His research interests are in open innovation, customer co-creation, digital media, knowledge creation, service design, healthcare and strategic marketing. Dominik's publications have appeared in journals like Journal of Product Innovation Management, Journal of Service Research, BMJ Quality \& Safety (previously Quality \& Safety in Health Care), Health Policy and Research Policy. Dominik Mahr is the corresponding author and can be contacted at: d.mahr@ maastrichtuniversity.nl

Nikos Kalogeras is an Assistant Professor of Marketing-Finance and co-director of the Marketing-Finance Research Lab at the Department of Marketing and Supply Chain Management of the School of Business and Economics, Maastricht University. He is also an Adjunct Professor of Marketing-Finance \& Decision Sciences at the Mediterranean Agronomic Institute of Chania, CIHEAM, Greece. His research interests mainly focus on individual market participants' (producers, consumers, investors) behavior regarding strategic marketing and financial decisions. He has published more than 20 articles in international journals and academic books (e.g. Food \& Chemical Toxicology, European Journal of Operational Research, Journal of Food Engineering, Agribusiness: An International Journal, International Journal of Food \& Agribusiness Marketing, Supply Chain \& Finance) and co-authored several book chapters and conference proceedings.

Gaby Odekerken-Schröder is a Professor in Customer-Centric Service Science at Maastricht University. She is the Scientific Director of Maastricht University's SSF, the place where academia meets business to create innovative services, and she is the Vice-Chair of the Department of Marketing and Supply Chain Management of Maastricht University. Her main research fields are services and relationship marketing. Her research has been published in Journal of Marketing, Journal of Retailing, Journal of Service Research, Journal of Business Research, International Marketing Review, European Journal of Marketing, Journal of Retailing and Consumer Services, Journal of Consumer Marketing and many other international journals. Her teaching time is dedicated to developing high quality courses for Bachelor, Master, $\mathrm{PhD}$ and executive students.
A service science
approach

471

To purchase reprints of this article please e-mail: reprints@emeraldinsight.com Or visit our web site for further details: www.emeraldinsight.com/reprints 